OPEN ACCESS

Edited by:

Brian Dixon,

University of Waterloo, Canada

Reviewed by:

Gregory D. Wiens, Agricultural Research Service,

United States Department of

Agriculture, United States

Alberto Cuesta,

University of Murcia, Spain

*Correspondence:

Tom Goldammer

Tom.goldammer@uni-rostock.de

Specialty section:

This article was submitted to

Comparative Immunology,

a section of the journal

Frontiers in Immunology

Received: 12 July 2019

Accepted: 04 September 2019

Published: 20 September 2019

Citation:

Rebl A, Rebl H, Verleih M, Haupt S,

Köbis JM, Goldammer T and

Seyfert H-M (2019) At Least Two

Genes Encode Many Variants of Irak3

in Rainbow Trout, but Neither the

Full-Length Factor Nor Its Variants

Interfere Directly With the

TLR-Mediated Stimulation of

Inflammation.

Front. Immunol. 10:2246.

doi: 10.3389/fimmu.2019.02246

\section{At Least Two Genes Encode Many Variants of Irak3 in Rainbow Trout, but Neither the Full-Length Factor Nor Its Variants Interfere Directly With the TLR-Mediated Stimulation of Inflammation}

\author{
Alexander Rebl ${ }^{1}$, Henrike Rebl ${ }^{2}$, Marieke Verleih ${ }^{1}$, Stephanie Haupt ${ }^{1}$, Judith M. Köbis ${ }^{1}$, \\ Tom Goldammer ${ }^{1 *}$ and Hans-Martin Seyfert ${ }^{1}$ \\ ${ }^{1}$ Fish Genetics Unit, Leibniz Institute for Farm Animal Biology (FBN), Institute of Genome Biology, Dummerstorf, Germany, \\ ${ }^{2}$ Department of Cell Biology, Rostock University Medical Center, Rostock, Germany
}

The interleukin-1-receptor-associated kinase 3 (IRAK3) is known in mammals as a negative feedback regulator of NF-kB-mediated innate-immune mechanisms. Our RNA-seq experiments revealed a prototypic 1920-nt sequence encoding irak3 from rainbow trout (Oncorhynchus mykiss), as well as 20 variants that vary in length and nucleotide composition. Based on the DNA-sequence information from two closely related irak3 genes from rainbow trout and an irak3-sequence fragment from Atlantic salmon retrieved from public databases, we elucidated the underlying genetic causes for this striking irak3 diversity. Infecting rainbow trout with a lethal dose of Aeromonas salmonicida enhanced the expression of all variants in the liver, head kidney, and peripheral blood leucocytes. We analyzed the functional impact of the full-length factor and selected structural variants by overexpressing them in mammalian HEK-293 cells. The full-length factor enhanced the basal activity of NF-kB, but did not dampen the TLR2-signaling-induced levels of NF- $\mathrm{KB}$ activation. Increasing the basal NF- $\mathrm{KB}$-activity through Irak3 apparently does not involve its C-terminal domain. However, more severely truncated factors had only a minor impact on the activity of NF-кB. The TLR2-mediated stimulation did not alter the spatial distribution of Irak3 inside the cells. In salmonid CHSE-214 cells, we observed that the Irak3-splice variant that prominently expresses the C-terminal domain significantly quenched the stimulation-dependent production of interleukin-1 $\beta$ and interleukin-8, but not the production of other immune regulators. We conclude that the different gene and splice variants of Irak3 from trout play distinct roles in the activation of immune-regulatory mechanisms.

Keywords: CHSE-214, GFP expression plasmid, IRAK-3, salmonid fishes, Toll-like receptor signaling 


\section{INTRODUCTION}

The immune system of vertebrates enables rapid, very efficient, and sustainable defense against microorganisms and viruses. Shortly after the detection of pathogens, amplifier mechanisms boost various destructive activities, which may also be directed against the host itself. To avoid such pathophysiological conditions, the immune system is tightly regulated by a vast number of inhibitory factors (1). One of the factors that counteracts pro-inflammatory processes is the interleukin-1receptor-associated kinase 3 (IRAK3) alias IRAK-M. In general, all four IRAK-family members (IRAK1-4) are composed of four defined regions: an N-terminal death domain, the ProST region, which is rich in proline, serine, and threonine residues, and a kinase domain adjacent to the C-terminal region (2-5). In contrast to IRAK3, the IRAK-family members $-1,-2$, and -4 positively regulate inflammatory processes. While mammalian species express all four IRAK paralogs, genomes of several non-mammalian vertebrates feature only one or two IRAK paralogs (2). An IRAK3 ortholog has, for instance, been lost in sauropsidia, amphibians $(2,6)$, and several fish species.

The IRAK proteins are constituents of the multimeric signaling complex "myddosome" (7) that transfers the pathogenrelated signals from toll-like receptors (TLRs) $(8,9)$ to downstream factors. These include TRAF6 ("tumor necrosis factor alpha"-receptor-associated factor 6), which is crucially involved in releasing active NF- $\mathrm{kB} /$ Rel proteins from their inhibitors (10). These key activators of transcription control hundreds of pro-inflammatory immune genes (11), such as the cytokine genes interleukin- $1 \beta$ (IL1B) and interleukin-8 (CXCL8).

The structural basis for the different regulatory roles of the four IRAK proteins lies in an amino-acid exchange. While an aspartic-acid residue is vital for the catalytic activity of the kinase domain in the human IRAK1 and-4 factors (12), this position is substituted with an asparagine residue in human IRAK2 and a serine residue in human IRAK3 (Ser-293) $(3,12)$. The latter exchange knocks down kinase activity, so IRAK3 contains only a "pseudokinase domain."

The interleukin-1-receptor-associated kinase 3 (IRAK3) is thought to block the TLR-dependent activation of NF- $\mathrm{KB}$ proteins and MAP kinases $(13,14)$ and contribute to establishing tolerance to microbial components such as endotoxins (15-18). Two mechanisms have been postulated in this regard. LynKew suggested that IRAK3 allows the epigenetic remodeling of chromatin by affecting the expression of histone deacetylase 2 , which silences the synthesis of pro-inflammatory effectors (19). Zhou and co-workers proved in mice that IRAK3 may interact

\footnotetext{
Abbreviations: Aa, amino acid; GFP, green-fluorescent protein; hpi, hours postinfection; INPP5D, inositol polyphosphate-5-phosphatase D; IRAK, interleukin-1 receptor-associated kinase; LPS, lipopolysaccharide; NF-kB, nuclear factor "kappalight-chain-enhancer" of activated B-cells; NFKBIA, NF-KB inhibitor, subunit alpha; nt, nucleotide(s); PI, propidium iodide; qRT-PCR, quantitative reverse transcriptase polymerase chain reaction; SNC, single nucleotide change; SNP, single-nucleotide polymorphism; SOCS, suppressor of cytokine signaling; TIR, Toll/interleukin-1 receptor resistance; TLR, Toll-like receptor; TNFAIP3, tumor necrosis factor alpha-induced protein 3; TRAF6, tumor necrosis factor alpha receptor-associated factor 6; UTR, untranslated region.
}

with IRAK4 to form the so-called "IRAK-M myddosome" (5). This specific variant of the complex mediates a secondwave of NF-kB activation that induces the expression of genes encoding anti-inflammatory molecules like SOCS1 (suppressor of cytokine signaling 1), INPP5D (inositol polyphosphate-5phosphatase D alias SHIP1), TNFAIP3 (TNF alpha-induced protein 3 alias A20), and NFKBIA (NF- $\kappa$ B inhibitor alpha alias $\mathrm{I} \kappa \mathrm{B} \alpha)(5,17)$. Eventually, these counterbalancing factors prevent the progression of a "cytokine storm" and contribute to the resolution of inflammation (20).

Two components of the putative myddosome of rainbow trout (Oncorhynchus mykiss) have already been characterized by our group, the TLR adapter myd88 and its binding partner irak4 (2123). So far, irakl has not been investigated in trout, but has in other fish species $(24,25)$, and irak2 has been lost in fish (26). The first mention of irak 3 as a promising marker for the early immune response of zebrafish is found in a report by Stockhammer et al. (27), but it took another 9 years until the first Irak3 factor was structurally und functionally characterized in a (serranid) fish species (28).

Meanwhile, we also began analyzing the structure and function of Irak 3 from rainbow trout, but we encountered several problems. First and above all, we consistently obtained irak 3 amplificates with various irak3-specific PCR primers, which all showed atypical shoulder peaks in melting-curve analysis, indicating the presence of various isoforms. We wondered (i) how many Irak3 variants are expressed in trout, (ii) how would they differ structurally, and (iii) what physiological effects the different variants might cause during the immune response of trout. The present report characterizes more than 20 irak3-mRNA isotypes including their splice variants from rainbow trout. We expressed four structurally very different irak3 transcripts in two cell models and quantified their potential to interfere with immune-activating mechanisms.

\section{MATERIALS AND METHODS}

\section{Identification of Irak3-Encoding Sequences in RNA-Seq Datasets From Rainbow Trout}

At the outset of our investigations of an IRAK3 ortholog in salmonid fish, no full-length cDNA sequence for any teleostean ortholog was known. Therefore, we performed a BLAST search against the next-generation RNA-sequence reads of rainbow trout $O$. mykiss, which had been generated in our institute using the Illumina RNA-seq technology. The procedure is only briefly presented below, since a more detailed presentation of the experiment has already been published elsewhere (29). Total RNA was extracted from six tissues (gills, head kidney, heart, liver, spleen, white muscle) of rainbow trout. Trout were 10-11 months in age with an average weight of $333.0 \pm 54.9 \mathrm{~g}$. Library constructions followed the TruSeq RNA Sample Preparation v2 Guide supplied with the TruSeq RNA Sample Prep Kit v2 (Illumina) with minor modifications. Three micrograms of total RNA were purified, fragmented, and then used as template for cDNA synthesis. Subsequently, Illumina paired-end adapters were ligated to the $3^{\prime}$-adenylated cDNA ends. After determining 
their DNA concentrations, the libraries of each tissue from eight individuals per strain, marked with distinct adapters, were loaded into separate Illumina-flow cells. Thirty-six sequencing cycles were conducted on an Illumina Genome Analyzer using the Multiplex Paired-End-Sequencing kits (Illumina). The resulting short-sequence reads were filtered for quality by our in-house Linux program FILTRIX (unpublished). The filter steps included the removal of adapter sequences to trim away low-quality regions and merge overlapping reads. Based on this primary-data analysis comprising 332 million high-quality sequencing reads of the trout transcriptome, we used the bioinformatics software Unipro UGENE v1.16 (30) to search for irak3 reads.

\section{Isolation and Cloning of Multiple Irak3-Sequences From Rainbow Trout}

To isolate the cDNA sequences that encode the entire openreading frame (ORF) of irak3 and its supposed variants, we reverse-transcribed total RNA extracted from various rainbow-trout tissues (see above) using a GeneRacer Kit (ThermoFisherScientific) and the SuperScript II Reverse Transcriptase (ThermoFisherScientific). Forward primers were placed on the $5^{\prime}$-UTR immediately upstream of the translational start codon and the reverse primers on the $3^{\prime}$-UTR, downstream adjacent to the translational stop codon (full-length, sense f1: 5'-TAAGGTTCCAGCTCAGTCGC-3', antisense r1: 5'-GAT TAGGATTCGGGAGGGCA-3'; truncated, sense f2: $5^{\prime}$-CGCA GTTGAGATGGACTCGTC-3', antisense r2: 5'-ACATTGGT TTCCTTACCCTGTCA-3'). In a standard-PCR reaction using the OneTaq DNA Polymerase (New England Biolabs) and a pool of previously generated cDNAs as template, we retrieved fragments of up to $\sim 2 \mathrm{~kb}$.

In addition, we performed $3^{\prime}$-RACE experiments to elucidate the $3^{\prime}$-end sequence of the truncated irak 3 variants. To this end, we used the sense RACE-primer f1 $5^{\prime}$-AAGCTGTCTGAT TTTGGGACGG-3' derived from the $5^{\prime}$-region of exon $9\left(5^{\prime}\right.$ upstream of the site where the coding region of the truncated irak 3 variant terminates) and a nested RACE-primer f2 $5^{\prime}$-TGC CGGAGGAATACATACGATG-3' located further downstream on the same exon. An oligo(d)T oligonucleotide served as antisense primer. All PCR amplicons were cloned into pGEM$\mathrm{T}$ Easy vector (Promega) and sequenced using the MegaBACE capillary sequencer (GE Healthcare). Each nucleotide position was sequenced at least four times.

\section{In-silico Structural Characterization of Irak3 Variants}

Global sequence alignments were performed using the EMBOSS/Stretcher tool (https://www.ebi.ac.uk/Tools/psa/ emboss_stretcher/). Phylogenetic analyses were conducted using the Molecular Evolutionary Genetics Analysis package MEGA7 (31). We first clipped all irak3 sequence files at position 994 in exon 9 (relative to the first coding nucleotide of variant a), which represents the common fragment of the truncated and full-length Irak3-encoding cDNAs and then subjected these to multiple alignment using the ClustalW algorithm. The dendrogram was reconstructed using the neighbor-joining method based on the maximum-likelihood method. The tree with the highest log likelihood (-1338.9) was chosen and optimized manually. The online tool Microsatellite Repeats Finder (http://insilico.ehu. es/mini_tools/microsatellites/) was used to identify repetitive elements in the genomic DNA. Functional motifs and domains of conceptually translated (Expert Protein Analysis System proteomics server, Swiss Institute of Bioinformatics; http://www. expasy.ch/) amino acid (aa) sequences were identified using the NCBI (National Center for Biotechnology Information; http:// blast.ncbi.nlm.nih.gov/) algorithm in accordance with results from the search with SMART (Simple Modular Architecture Research Tool; http://smart.embl-heidelberg.de/). The threedimensional (3D) structures of particular Irak3 variants were predicted by the Protein Homology/analogY Recognition Engine V 2.0 (Phyre ${ }^{2}$ ) (32) and visualized using OpenRasMol software (33).

\section{Establishment of Irak3-Expression Plasmids}

We constructed the plasmids that express the full-length irak3 factor $(\mathrm{m})$ and its variants $\left(\mathrm{a}, \mathrm{g}, \mathrm{h}, \mathrm{k}, \mathrm{l}\right.$, and $\left.\mathrm{m}^{\prime \prime}\right)$ from rainbow trout to analyze their ability to interfere with TLR-dependent NF$\kappa \mathrm{B}$ activation in in-vitro models. In the first step, we designed variant-specific oligonucleotide primers featuring restriction sites for HindIII and EcoRI at their $5^{\prime}$ and $3^{\prime}$ ends, respectively. Subsequently, a standard-PCR reaction using cDNA from rainbow trout as template was conducted using the common sense primer $5^{\prime}$-ACCCAAGCTTGATATGGACTCGTCTATG TACCTGTA- $3^{\prime}$ and the antisense primer $5^{\prime}$-TCAGAATTCCTCC TGGGTGGTCATGGAGA-3' specific for variants $\mathrm{m}$ and $\mathrm{m}^{\prime \prime}$ or the antisense primer $5^{\prime}$-TCAGAATTCAAAGCATCGTATGTAT TCCTCCG- $3^{\prime}$ specific for variants a and 1 (restriction sites of all primers are underlined). The resulting amplicons were inserted into pGEM-T Easy Vector (Promega). This subclone was digested with HindIII and EcoRI at $37^{\circ} \mathrm{C}$ overnight. The retrieved fragments were finally inserted "in frame" into our expression vector 280, a modified (34) CMV-driven $\mathrm{pKS}(+)$ Bluescript plasmid (Promega).

To analyze the intracellular spatial distribution, we tagged the full-length Irak3 factor $\mathrm{m}$ and its variants a and $\mathrm{m}^{\prime \prime}$ with fluorescent labeling. Then, we digested the irak3- $a,-m$ and $-m^{\prime \prime}$ subclones with HindIII and EcoRI at $37^{\circ} \mathrm{C}$ overnight and inserted the retrieved fragments into the respective cloning sites of plasmid pAM505, which expresses the green fluorescent protein (GFP; AF140578) under the control of the CMV promoter.

All plasmids were prepared with endotoxin-free reagents (EndoFree Plasmid Maxi Kit; Qiagen) and sequenced to confirm their appropriate construction.

\section{Cell Culture, Transfection, and Luciferase Assay}

The human embryonic kidney-cell line HEK-293 (ATTC) and the embryonic cell line CHSE-214 from Chinook salmon Oncorhynchus tshawytscha (Sigma-Aldrich) were cultured in EMEM medium (Sigma-Aldrich), supplemented with 10\% fetal calf serum (PAN), 1\% non-essential aa (Biochrom), and $2 \mathrm{mM}$ 
L-glutamine (Biochrom). The two cell lines were cultured in humidified atmosphere containing $5 \% \quad \mathrm{CO}_{2}$, at either $37^{\circ} \mathrm{C}$ (HEK-293) or $20^{\circ} \mathrm{C}$ (CHSE-214). Prior to and during the stimulation experiments, both cell lines were proven to be free of mycoplasma contamination using the Lookout Mycoplasma PCR detection kit (Sigma-Aldrich).

Endotoxin-free preparations of the expression constructs were transfected into HEK-293 cells using Lipofectamin 2000 (ThermoFisherScientific). For these co-transfection assays, we used $50 \mathrm{ng}$ of the ELAM-driven NF- $\mathrm{BB}$-reporter vector and increasing concentrations (50, 500, 2,000 ng) of the respective irak3-expression constructs. Since the HEK-293 cells do not express most TLRs (35), $200 \mathrm{ng}$ of the plasmid that expresses bovine TLR2 (34) were co-transfected. The total DNA concentration was adjusted to $4,100 \mathrm{ng}$ /assay by adding the empty cloning vector. After transfection, the cells were distributed into six wells of a 24 -well plate. Three wells were left as unstimulated controls. The other three wells were stimulated for $24 \mathrm{~h}$ with the TLR2 ligands $\mathrm{Pam}_{2} \mathrm{CSK}_{4}(10 \mathrm{ng} / \mathrm{ml}$, Invivogen) and FSL-1 (100 ng/ml, Invivogen) or with heat-killed bacteria Escherichia coli, strain $1303(30 \mu \mathrm{g} / \mathrm{ml})$. The luciferase activity of HEK-293-cell lysates was measured with the Dual-Luciferase Reporter Assay System (Promega) with the Lumat LB 9501 luminometer (Berthold). Values were normalized against the protein concentration as determined using the NanoDrop 2000 photometer (ThermoFisherScientific). Every transfection was assayed in triplicate; each transfection experiment was performed at least twice.

CHSE-214 cells were transfected with 2,000 ng of the plasmid that expresses trout irak3 variants a, $1, \mathrm{~m}$, and $\mathrm{m}^{\prime \prime}$ using X-tremeGENE HP DNA Transfection Reagent (Roche/SigmaAldrich). Since CHSE-214 cells endogenously express Tlr3 and Tlr5 (36), we stimulated them for 3 or $6 \mathrm{~h}$ with a mixture of the TLR3 ligand poly(I:C) of low molecular weight $(10 \mu \mathrm{g} / \mathrm{ml}$, Invivogen) and the TLR5 ligand flagellin from Salmonella typhimurium (100 ng/ml, Invivogen). These incubation times and doses were determined in pre-tests. After the stimulation period, cells were harvested in ice-cold PBS for RNA isolation and the subsequent profiling of immune-gene expression.

\section{Confocal Microscopy and Determination of Cell Viability}

HEK-293 cells were transfected with $1 \mu \mathrm{g}$ of plasmid expressing the GFP-tagged factors. Optionally, transfected cells were stimulated for $30 \mathrm{~min}$ with $10 \mathrm{ng} / \mathrm{ml} \mathrm{Pam}_{2} \mathrm{CSK}_{4}$ prior to observation with fluorescence microscopy using the confocal microscope LSM 780 (Carl Zeiss Microscopy), equipped with a $63 \times$ oil-immersion DIC objective and an incubation chamber to maintain $\sim 37^{\circ} \mathrm{C}$ and $5 \% \quad \mathrm{CO}_{2}$ during the microscopic investigations. Nuclei were stained by adding Hoechst 33342 dye $(1 \mu \mathrm{g} / \mathrm{ml}$, Sigma-Aldrich) to the medium for $30 \mathrm{~min}$, immediately before the start of the observation. Quantification of the live/dead ratio of transfected cells was performed with the Nucleocounter3000 (Chemometec). Dead cells were stained using propidium iodide (PI, $1 \mu \mathrm{g} / \mathrm{ml}$ ). The fluorescence microscopic observation of the HEK-293 cells overexpressing the full-length (m), truncated (a), or splice $\left(\mathrm{m}^{\prime \prime}\right)$ irak3 variants were repeated at least twice with different plasmid preparations.

\section{Quantitative Real-Time Expression Analyses of in vivo and in vitro Samples}

The correlation between IRAK3-transcript and protein levels has been proven (16). For expression profiling, we designed a panel of transcripts that encode inflammatory and inhibitory factors from trout, including the primers that discriminate between different irak3 transcripts (Table 1). To determine the abundance of the entirety of irak3 transcripts, we designed oligonucleotide primers specific to exon 1 of the irak3 gene (covering the region between positions 2 and 95 on the coding sequence of all unspliced variants) sharing perfect sequence identity across the multiple variants. A second pair was placed on exons 10 and 11 (positions 1,136 to 1,298 on the coding sequence of factors $m$ and $n$ ), which are absent in all truncated variants, to quantify the abundance of the full-length transcripts.

To profile the infection-modulated irak3 expression, we followed the principles of the 3Rs (37) for ethical use of animals and utilized samples from a previous experiment. Here, rainbow trout were infected with $1 \times 10^{7}$ Aeromonas salmonicida ssp. salmonicida (approved animal experiment, LALLF MV/TSD/7221.3-2.5-008/10.). The peritoneal injection has been previously described (22). Tissue samples from peripheral blood leucocytes (PBLs), head kidney and liver were used from four individuals at $0,6,12$, and $24 \mathrm{~h}$ post-infection. The RNA was isolated from these samples in separate tubes using TRIzol (Invitrogen) and subsequently purified with the ISOLATE II RNA Micro Kit (Bioline). After cDNA synthesis, the concentrations of the individual cDNA aliquots were adjusted at $10 \mathrm{ng} / 5 \mu \mathrm{l}$. Samples were than measured using the Biomark/Fluidigm. To this end, cDNAs were individually preamplified in 10 cycles using the PreAmp Master Mix (Fluidigm) and subsequently treated with exonuclease I (New England BioLabs) to degrade single-stranded oligonucleotide primers. Finally, multiplex RT-qPCR was conducted using the 48.48 Fluidigm Gene Expression biochips, which were first primed in the MX IFC Controller (Fluidigm). Then they were loaded with the pre-amplified cDNA samples and eventually analyzed using the Biomark HD system with the manufacturer's thermal protocol "GE Fast 48 × 48 PCR+Melt v2.pcl." EvaGreen fluorescence dyes (Bio-Rad) served as DNA-binding reporter molecules to allow for the quantification of the amplified target fragments.

The LightCycler-96 system (Roche) was used to quantify the expression of transcripts encoding inflammatory and inhibitory factors in stimulated and control CHSE-214 cells. The LightCycler protocol was optimized for a $12-\mu 1$-reaction volume using $6 \mu \mathrm{l}$ SensiFAST SYBR No-ROX Mix (Bioline), $5 \mu \mathrm{l} \mathrm{cDNA}$, and $1 \mu \mathrm{l}$ primers. The qPCR program included an initial denaturation $\left(95^{\circ} \mathrm{C}, 5 \mathrm{~min}\right.$.), followed by 40 cycles of denaturation $\left(95^{\circ} \mathrm{C}, 5 \mathrm{~s}\right)$, annealing $\left(60^{\circ} \mathrm{C}, 15 \mathrm{~s}\right)$, and elongation $\left(72^{\circ} \mathrm{C}, 15 \mathrm{~s}\right)$, as well as the fluorescence measurement $\left(72^{\circ} \mathrm{C}, 10 \mathrm{~s}\right)$.

All melting curves were analyzed individually to validate the absence of unspecific products. Amplicons were visualized 
TABLE 1 | Gene-specific primers used for RT-qPCR assays.

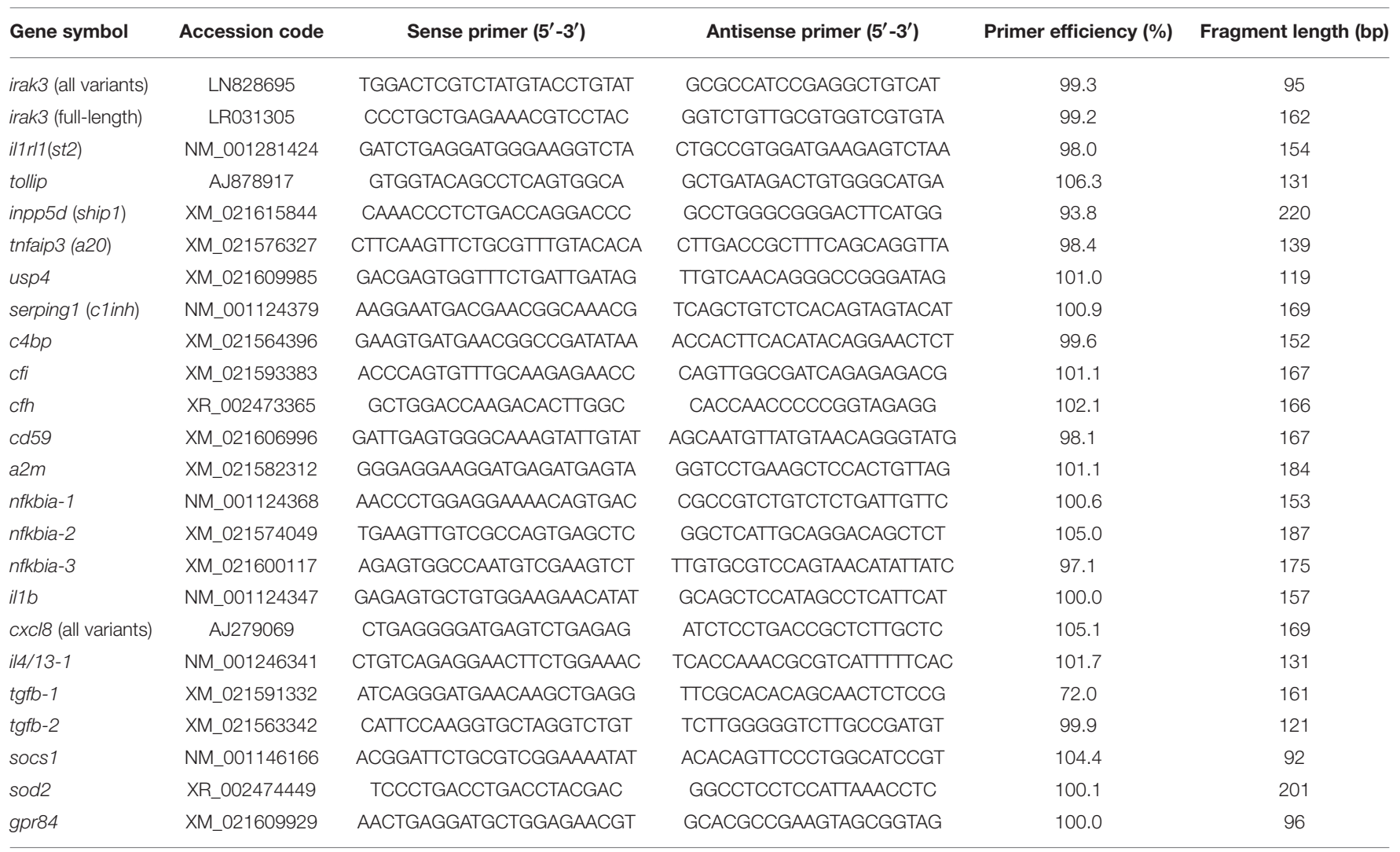

on agarose gels in order to assess product size and quality. Crossing points (CP) between 5 and 35 cycles were considered detectable. The obtained real-time data were all normalized with a factor based on the geometric mean values from three potential reference genes. The $\mathrm{qBase}+$ software (Biogazelle, Ghent University, Belgium) validated the suitability of the quantified reference genes, eukaryotic translation elongation factor eef1a1 (38), ribosomal protein rps5, and $18 \mathrm{~S}$ ribosomal RNA (39), for data normalization. Individual copy numbers were calculated based on external gene-specific standard curves $\left(10^{7}-10^{3}\right.$ copies per $\left.5 \mu \mathrm{l} ; R^{2}>0.999\right)$.

\section{RESULTS}

From our 332 million RNA-sequencing reads from rainbow trout, we derived an ORF that encodes a 1920-nt comprising irak3-cDNA sequence. This trout sequence resembles reasonably well the human IRAK3-encoding sequence $(\sim 52 \%$ nucleotidesequence identity) and the IRAK3 ortholog in orange-spotted grouper Epinephelus coioides ( $63 \%)$, which represents the first published example of an IRAK3 ortholog from teleost fish. The aa sequence derived from the conceptually translated cDNA shares $>96 \%$ similarity with those from segments of the factor encoded by salmon and on average approximately $60 \%$ similarity with the ortholog factors from a wide range of fish species. The similarity of the Irak3-aa sequences is only about $40 \%$ in comparison to mammalian species.

\section{Two irak3 Genes in Rainbow Trout Share Structural Similarities}

Inquiring into the gene structure, we used our RNA-seq-derived irak3-prototype sequence to search for IRAK3 orthologs in the genome assemblies of rainbow trout (40-42) published by other groups and consortia. We identified two relevant entries for genomic trout sequences, (i) irak3 (Gene ID: 101268966) on an unplaced scaffold (MSJN01015042, MSJN01016613, MSJN01023158) and (ii) LOC110499741/irak3-like (Gene ID: 110499741) on chromosome 21 (MSJN01004319). Comparing our cDNA sequence with these two different genomic deposits revealed that the latter, not contiguous sequence file consecutively comprises 13 exons that encode Irak3. Their lengths vary between 63 and 472 nt (excluding UTRs; Figure 1, upper scheme). The alignment of these exon sequences with the formerly mentioned three other genomic irak3-sequence files showed that they altogether harbor exons 1, 2, 5-7, and 9-13. The thus proven segmentation of the irak3-encoding gene from trout into 13 exons complies with a recent report on a homologous irak3-gene structure in grouper (28).

We compared the genomic sequences of both irak3 genes from rainbow trout in order to understand if they stem from two different genes. The exon sequences are highly similar (>98\% sequence identity). Due to large sequence gaps in both of the irak3 genes, we conducted local alignments of comparable intronic fragments, which yielded identities between 90 and 99\%. While this high degree of sequence similarity indicates their 


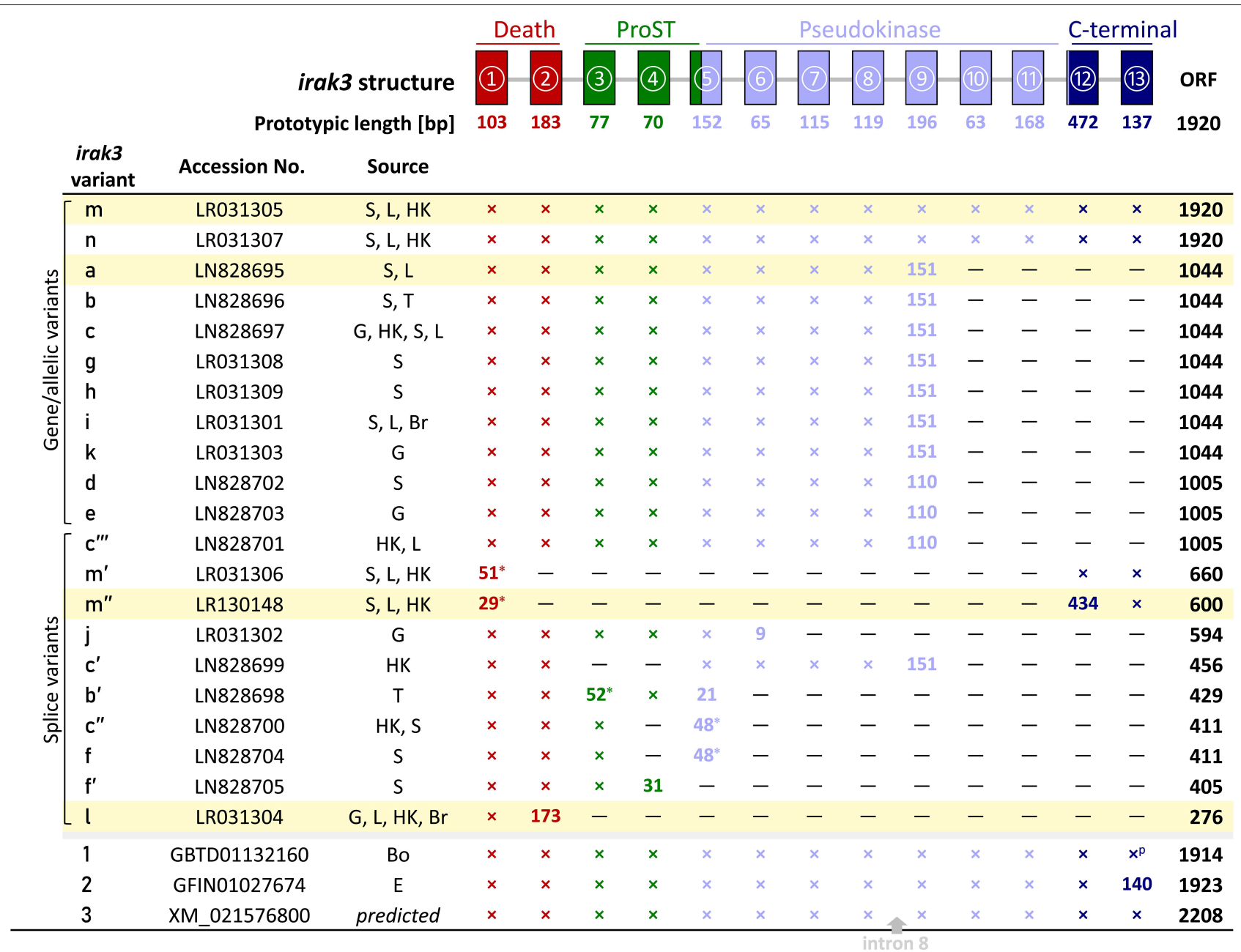

FIGURE 1 | Representation of the different irak3-transcript lengths. The irak3-variants of trout are listed together with their accession numbers and their tissue-wise occurrence on the left. Tissues are abbreviated as follows: Bo, bone; Br, brain; E, unfertilized eggs; G, gills; HK, head kidney; L, liver; S, spleen; T, thymus. The genomic organization of the trout irak3 gene is drawn above the scheme. Exons are represented by colored boxes (red, death domain; green, ProST region; light blue, pseudokinase domain; dark blue, C-terminal domain). Lines between exons represent introns. A cross indicates that the respective exon is present in the listed transcript variant; if the exon length differs from the prototypic length, the actual length is given (in nt); a superscript p denotes a partial $3^{\prime}$-end. The position where a fragment of intron 8 was inserted in the predicted irak3 variant (3) is marked with a gray arrow. Asterisks indicate the possible usage of alternative splice acceptor/donor sites. The color of the characters denotes a particular protein domain. Fields highlighted in yellow indicate clones, which were functionally analyzed in later experiments (see Figures 5-7).

close relatedness, clear differences exist, and validate that they do belong to two different genes. For instance, the positions of the partially degenerated micro- or minisatellites within the intronic sequences appear to be conserved in both genes, albeit slightly altered (Table 2). Remarkably, we found repetitions of coding sequences in the introns of both irak 3 genes. For instance, the $5^{\prime}$-most 15 to $17 \mathrm{nt}$ of exon 5 are repeated four times in intron 4 , directly upstream of exon 5. Intron 7 of the irak 3 gene from trout features three tandem repetitions of exon 7 in a row, separated by a longer $(>700 \mathrm{nt})$ and a shorter $(314 \mathrm{nt})$ non-coding intronic sequence, each flanked by the canonical $5^{\prime}-$ GT donor and $3^{\prime}-\mathrm{AG}$ acceptor dinucleotide splice sites. Similarly, a short fragment of exon 9 resides in intron 10, again flanked by core splice sites. Nonetheless, both deposits of genomic trout sequences for irak3 and LOC110499741/irak3-like gene still contain gaps of unknown lengths in introns $1,2,3,4,11$, and 12 .

\section{More Than 20 irak3-Transcript Variants of Different Lengths Were Cloned From} Rainbow Trout

We detected as many as 45 single nucleotide changes (SNCs) between nt positions 106 and 1,913 (numbering the first nucleotide of the translational start codon ATG as position 1) in our RNA-seq-derived irak3-consensus sequence (Figures 2A,B). To validate the variable nt positions in the irak3 sequences of trout, we derived irak3-specific oligonucleotides (Figure 2A) from our prototype-irak3 sequence for subsequent PCRs. 
TABLE 2 | Repetition of DNA elements (at least four-fold) within trout irak3 genes (bases follow the standard IUPAC nucleotide codes).

\begin{tabular}{|c|c|c|c|}
\hline Accession number & Intron \# & Motif sequence & Repetition \\
\hline \multicolumn{4}{|c|}{ Irak3 (Gene ID: 101268966): } \\
\hline NW_018531519 & 1 & TGAG & 11 \\
\hline NW_018531519 & 1 & AATSGAATCYGACACCGGASTCCCTAGTCNCTACWGTTA & 7 \\
\hline NW_018536133 & 4 & TACMACAGACT(GAT)GWTGTGTTSAGATGGTCCCTAGT & 7 \\
\hline NW_018536133 & 7 & TACTCCASCATTTAGATGGTTTCTSTATGTCTAMM & 12 \\
\hline NW_018536133 & between 7 and 12 & KRACTACYTATAGAC(T)(R) & 18 \\
\hline NW_018536133 & between 7 and 12 & TAACWNCCWMTARAN(T)(R) & 29 \\
\hline \multicolumn{4}{|c|}{ LOC110499741/irak3-like (Gene ID: 110499741): } \\
\hline MSJN01004319 & 1 & AGTG & 7 \\
\hline MSJN01004319 & 4 & TACATTAGATTRCTGAG(A) & 25 \\
\hline MSJN01004319 & 4 & GTAGAAACCACAGGCKTAGTGTTT(T)YAYTCTGTTKCTAG & 5 \\
\hline MSJN01004319 & 6 & ATGTCTAMCTACTCCATTAATCCTCCATTTKAGATGGTTTCTGT & $\geq 5$ \\
\hline MSJN01004319 & 7 & TGTTCCACAGACTGCATGACCAGGTGAGATATTCTATTCTMTACCCCTTACCTTCCCAAYGGATCWC & 4 \\
\hline MSJN01004319 & 7 & CTATTCTAGTTGTAKGTTGTGTTAC & 9 \\
\hline MSJN01004319 & 8 & TACCGGCTCAAACCCCTAGTCTATAACATCACAAGG & 8 \\
\hline MSJN01004319 & 8 & CAGTTAACCCACTGTTCCTAGRC & 5 \\
\hline MSJN01004319 & 11 & GT & 4 \\
\hline MSJN01004319 & 11 & RWAGCTWGGTGAATAYY & 31 \\
\hline MSJN01004319 & 12 & TAACTMCCTATAGAC(TR) & 16 \\
\hline
\end{tabular}

Amplicons were cloned and more than 100 clones were sequenced. The cloned sequences validated 23 of the 45 SNCs (Figure 2B). Surprisingly, we found that the lengths of the encoded ORFs eventually differed significantly, ranging from 276 to $1,920 \mathrm{nt}$ (Figure 1).

We named those varying irak 3 sequences in alphabetical order $(\mathrm{a}-\mathrm{m})$ according to their frequency in our clone collection and submitted them to the "European Nucleotide Archive" (ENA, project ID: PRJEB29555). The most abundant irak3-transcript variants encoded truncated versions of the prototypic 1,920-nt irak3 ORF (Figure 1, table). They contained ORFs comprising 1,044 or $1,005 \mathrm{nt}$, subsequently termed as variants a (NCBI accession code: LN828695), b (LN828696), c (LN828697), d (LN828702), e (LN828703), g (LR031308), h (LR031309), i (LR031301), and $\mathrm{k}$ (LR031303). The variants $\mathrm{m}$ (LR031305) and $\mathrm{n}$ (LR031307) represent full-length irak3 transcripts complying with two trout irak3 sequences, which have been submitted to the ENA database (GBTD01132160 and GFIN01027674). Our two full-length sequences and those two derived from the database share an overall identity of $>98 \%$, differing in 20 positions due to those SNCs and a triplet insertion at the $3^{\prime}$ end of file GFIN01027674. In addition, the above-mentioned genome-derived irak3-like sequence LOC110499741 from file XM_021576800 features an ORF comprising 2,208 nt and is hence $288 \mathrm{nt}$ longer than our cDNA-derived full-length irak3 sequences. This additional 288-nt sequence stems from a microsatellite [(TACCGGCTCAAACCCCTAGTCTATAACATCACAAGG) c.f. Table 2] that had been incorporated into the cDNA sequence, since it does not interrupt the ORF in conceptual translation. A bootstrap test of our phylogenetic analysis (Figure 2C) only confirmed the strong similarity of variants a and c (98\%) as well as of $\mathrm{j}$ and $1(86 \%)$. The cDNA sequence derived from the irak3-like gene LOC110499741 was clearly separated from the other 14 variants $(a-n)$, as well as from the sequences GBTD01132160 (termed here "1") and GFIN01027674 ("2") because of the insertion of the 288-nt microsatellite.

\section{Some Truncated Transcripts Are Caused by Alternative Splicing}

We found 10 shorter irak3 transcript variants (Figure 1), which are most likely splice variants of the full-length factor $\mathrm{m}\left(\mathrm{m}^{\prime}\right.$, LR031306, $\mathrm{m}^{\prime \prime}$, LR130148) or the truncated variants $\mathrm{b}\left(\mathrm{b}^{\prime}\right.$, LN828698), c ( $c^{\prime}$, LN828699; $c^{\prime \prime}$, LN828700; $c^{\prime \prime \prime}$ LN828701), f (LN828704, f' (LN828705), j (LR031302), and l (LR031304). Most likely, two mechanisms caused the further size reduction of the full-length and truncated irak3 transcripts. First, differential splicing exploited either the canonical splice sites GU and AG (variant $\mathrm{c}^{\prime}$ ) or alternative splice acceptor or donor sites located upstream of the commonly used dinucleotides $\mathrm{GU}\left(\mathrm{m}^{\prime}\right)$ or $\mathrm{AG}$ $\left(b^{\prime}, c^{\prime \prime}, f\right)$ shifted the ORF and provoked the incorporation of a pre-mature stop codon or shortened the exon size. Second, 


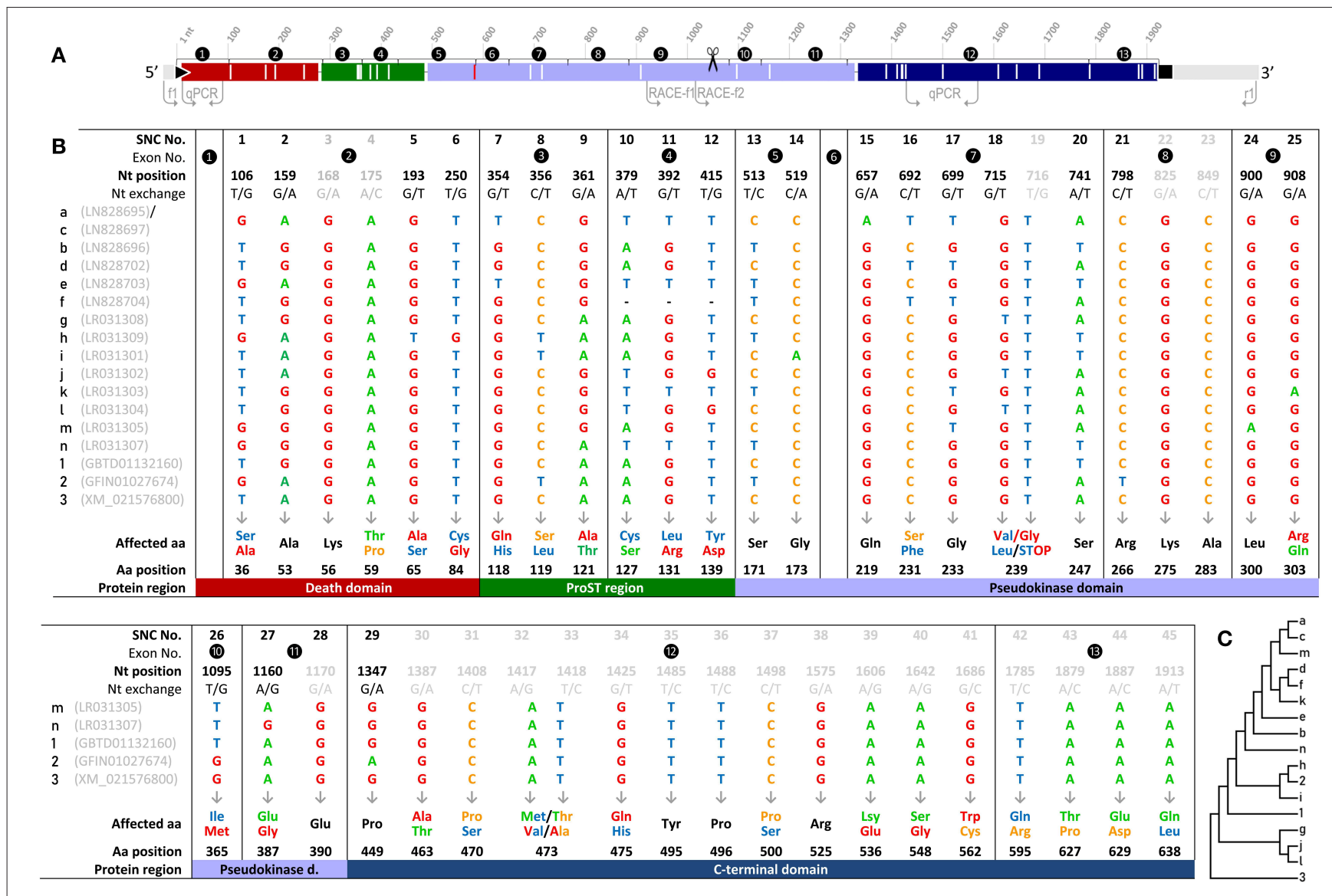

FIGURE 2 | (A) Schematic illustration of the irak3-cDNA variants. The encoded protein domains are colored as in Figure $\mathbf{1}$ (upper panel) and drawn to scale. Flanking light gray lines indicate UTR sequences; the black triangle and square mark the start and stop of the ORF, respectively. Non-synonymous SNCs are represented by longitudinal white lines; the longitudinal red line indicates the point mutation that leads to the shortened variant $j$. Arrows indicate the locations of the primers used for fragment amplification and the $3^{\prime}$-RACE. The scissors symbol indicates the end of the truncated irak3-cDNAs. (B) List display of the 45 SNCs in trout Irak3-encoding CDNA sequences predicted by RNA-sequencing and those confirmed via cloning. The SNCs are numbered in the first row together with their exon-related occurrences and the exact positions in the ORF, with "1" assigned to the first nucleotide of the translational start triplet. Twenty-three of the SNCs were also confirmed by sequencing 100 randomly picked clones from batch-cloned irak3 amplicons. SNCs not represented in that clone collection are shown in gray characters. Nucleotide variations and the affected aa residues are marked with the same colors (adenine, green; guanine, red; thymine, blue; cytosine, orange). Characteristic domains carrying the affected aa residues are indicated by differently shaded table fields. Note that variants a and $c$ share the same SNCs, but bear an additional nt exchange at position 407 (C) Dendrogram of trout irak3 cDNA variants. The bootstrap analysis of transcript relatedness involved 17 trout-specific nucleotide sequences (abbreviated as numbers and digits as indicated in (B) in the left column of the table).

a point mutation $(\mathrm{AAA} \rightarrow \mathrm{UAA}$, at position 591 ; variant $\mathrm{j}$ ) introduced a stop codon and lead to the pre-mature termination of the ORF.

\section{Some Truncated Transcripts Contain a Nonameric Sequence Absent in the Full-Length cDNA Sequence} The structural cause for the truncation of the irak 3 variants comprising the ORFs of 1,044 and 1,005 nt in length could not be explained based solely on the available DNA-sequence information. These truncated cDNA sequences feature a 9-ntsequence motif at the $3^{\prime}$-end of their ORFs that is not found in the copies of the full-length cDNAs, or in the available genomic DNA sequences from trout. To elucidate the origin of the truncated transcript variants, we performed $3^{\prime}$-RACE experiments with the sense primer RACE-f1 annealing to the $5^{\prime}$-region of exon 9 and the nested primer RACE-f2 annealing further downstream on the same exon (Figure 2A). The resulting $3^{\prime}$-RACE sequence (LR213462, Figure 3A) did not match either the full-length irak3-cDNA sequences of trout or the substantial amount of intronic sequence information from the irak 3 and the irak3-like genes. It shares instead a high identity with an irak3-like sequence from Atlantic salmon (LOC106609858, XM_014208880). The trout $3^{\prime}$-RACE sequence matches from position 16 (located in exon 9) to the $3^{\prime}$ end of the salmon irak3 UTR (positions 2,192-2,628) with $>86 \%$ similarity (Figure 3B). Remarkably, comparing both sequences revealed that a point mutation introduced a translational stop codon in the truncated irak3 variants from trout (Figure 3B, right side). The TGG triplet in the salmon sequence at positions 2,189-2,191 is converted into a TAG stop codon at positions 1,042-1,044 in the truncated irak3 variants $\left(a, b, b^{\prime}, c, c^{\prime}, c^{\prime \prime}, f, g, h, i, j, k\right.$, and l) from trout. Another noteworthy feature is a 275-nt long sequence residing in the 
3' UTR of both salmonid sequences (Figure 3C). Conceivably, this sequence stems from a retroposon element, since it is also present in many other genes from trout and salmon including such evolutionary unrelated genes as specc1, orail, eef1e1, anapc1, and morn3. This mobile genetic element must have been inserted into the ancestral salmonid irak3 gene, before the separation of the trout and salmon species.

\section{Irak3 Transcripts From Rainbow Trout Contain 45 Single Nucleotide Exchanges, but Only Three Different Alleles Were Found to Be Expressed in Individuals}

The 45 identified SNCs in the irak3-cDNA sequences from rainbow trout are not randomly distributed across the coding sequence (Figures 2A,B). Rather, no exchanges were found in exons 1 and 6 , whose coding sequences are strictly conserved. Moreover, exon 8 features only synonymous exchanges. The occurrence of the SNCs in the other exons does not follow an unambiguous pattern that would indicate any closer relatedness between the different irak 3 variants, as proven by our phylogenetic analysis (Figure 2C).

We tried to identify the minimal number of alleles from which the plethora of variants might possibly be encoded. To this end, we separately examined the irak 3 reads obtained from different tissues from each individual that was included in the RNA-seq analysis. We examined potential linkage groups formed by neighboring SNCs on the short 20-70-nt long reads and identified no more than three different SNC-linkage groups per individual. These individual linkage groups were expressed in all tissues analyzed. Hence, no tissue-specific linkage group was found, but SNC combinations did vary among the different individuals. Based on the assumption that one of these SNC combinations comes from the paternal allele and the other from the maternal allele, we conclude that the different alleles originated from (at least) two irak3 genes.

Taken together with the structural analysis of the two highly segmented irak3-encoding genes, which revealed the presence of duplicated/multiple exon copies and/or exon fragments, it seems likely that the various irak3 variants represent differentially spliced transcripts derived from only two irak3 genes.

\section{Several Irak3 Variants From Trout Lack Function-Relevant Domains and Amino-Acid Residues}

The full-length variants of irak3 in rainbow trout encode 639aa comprising proteins ( $m$, VDB38424; n, VDB38426), which contain the following domains in accordance with the structural characteristics of IRAK-family members (2-5): (i) a death domain (aa positions 4-96), (ii) a ProST region (aa positions 94-161), (iii) a pseudokinase domain (aa positions 164-442) and (iv) the C-terminal region (aa positions 444-639). Twentynine of the 45 SNCs mentioned above (almost two-thirds of the SNCs) represent non-synonymous mutations that contribute to a striking diversity of Irak3 variants in rainbow trout. Remarkably, the relative abundance of non-synonymous exchanges is very low in the pseudokinase domain at only $0.6 \%$, while it is significantly higher at in the ProST region (2.9\%), followed by the C-terminal domain (2.0\%) and the death domain (1.4\%). Even more diversity of Irak3 factors is caused through the length reduction of several variants. The Irak3 variants a to $\mathrm{k}$ are shorter by at least 292 aa residues compared with the full-length factors $m$ and $n$. The shortenings involve the deletion of about one third of the pseudokinase domain and the C-terminal domain (Figure 2A). In contrast, variants $\mathrm{m}^{\prime}$ and $\mathrm{m}^{\prime \prime}$ contain the complete C-terminal domain and a part of the death domain, but lack the entire pseudokinase domain.

The death domain is encoded by the first two coding exons of the irak3 and the irak3-like gene. Strikingly, the exon-1-encoded sequence is completely conserved in all irak3 variants, except the splice variants $\mathrm{m}^{\prime}$ and $\mathrm{m}^{\prime \prime}$ (Figure 1). The extremely short ORF of variant 1 (276 nt; Figure 1) only encodes an isolated death domain. The death domain of most other Irak 3 variants is followed by the ProST region. This region contains 11 proline (16\%), 15 serine (22\%), and 4 threonine residues (6\%) in a stretch of 69 aa residues. The relatively high abundance of these three aa residues corresponds approximately to those determined for all vertebrate IRAK proteins (43). Nevertheless, two of the vital ProST residues (Ser-119, Ser-127) are affected by base exchanges in some irak3 variants (a, c, e, h, i, j, k, n; Figure 1A).

The pseudokinase domain covers approximately the central half of the full-length Irak3 aa sequence from trout. This domain harbors the IRAK3-characteristic residue Asn-292, which is present in all full-length and truncated Irak3 variants, but absent in most splice variants $\left(\mathrm{m}^{\prime}, \mathrm{m}^{\prime \prime}, \mathrm{b}^{\prime}, \mathrm{c}^{\prime \prime}, \mathrm{f}, \mathrm{f}^{\prime}, \mathrm{j}\right.$, and $\left.\mathrm{l}\right)$. The $\mathrm{C}$ terminal domain is encoded by exons 12 and 13 and is therefore only present in the full-length factors $\mathrm{m}$ and $\mathrm{n}$ and their splice variants $\mathrm{m}^{\prime}$ and $\mathrm{m}^{\prime \prime}$.

\section{Infection With $A$. salmonicida Modulates the Expression of irak3 and Other Immunoregulatory Genes}

In healthy rainbow trout, the proportion of full-length transcripts within the entirety of all irak3-transcript variants varied in different tissues and cells: 29.1\% (liver), 33.7\% (head kidney), and $40.2 \%$ (PBLs) (Figure 4A). Hence, the transcripts that encode the full-length factor contribute much less than half of all irak3 transcripts.

We used samples from a previous infection trial with live $A$. salmonicida pathogens (44) to determine the infection-related regulation of the expression of inflammation inhibitors. The copy numbers of all irak3 variants were significantly elevated in the liver at 6 hpi and in the head kidney at 24 hpi (Figure 4A). The infection-related modulation of the irak3-transcript levels showed a significant $\sim 2.7$-fold increase in the liver and PBLs as early as $6 \mathrm{hpi}$ and an approximate doubling of the transcript number was recorded in the head kidney, but only as late as $24 \mathrm{hpi}$. The ratio of full-length vs. truncated irak3 variants was only slightly modulated during infection $(<10 \%$ variation in each tissue/cell type).

The modulations of the expression levels of other inhibitorencoding genes were also tissue-specific (Figure 4B). We detected in the head kidney very high transcript concentrations 


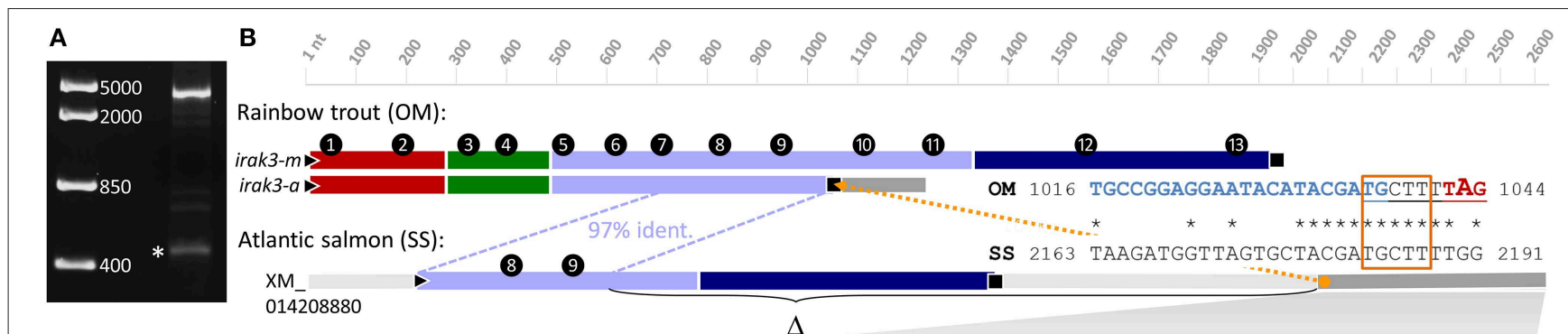

C om 30 GAAATCCAGCCCTGGTATGTGACGAGACGTGATGTTCATATGGTTGAATGAAAGCAATCTATGTCCTTCGTTGTCAGTAAATTATGCTAAA

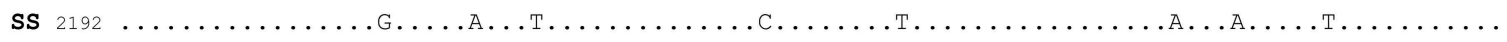
OM AA-ATATATTCTTGTAGAAAGTATTTATTATCTGCTGACAGATCCCATTTTATATTTCTTATTTATAAAATTAGGAAATGATTTATACAGTACT

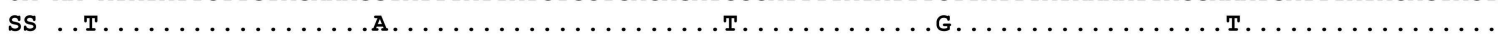
OM TCTATAATAAAAAACATTTTATAAAGATCATTTAAAATGACGGGTTCATGCAAAAATGTTAGCGTGTAGAAACAGTG----GGAAACTAAACCAA

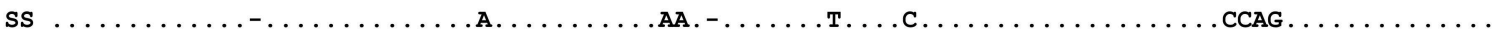
OM AGCATGAAGTGCTGTCATACCTTGTCCATAGGCCGCTGACAGGGTAAGGAAACCAATGTGTCATTTTGTAA-----------CTATCCCTTTACTT

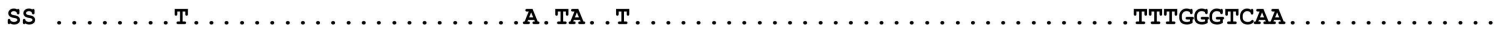
oM ATGTTTTGAAGATGACATT----TTTTTCATGCCTTTTATTAATAAAATAAGATTGACAATGAAAAAAAAAAAAAGAAAAAAAAA 472

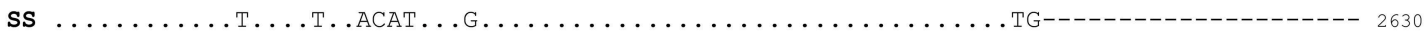

FIGURE 3 | (A) 3'-RACE experiments using sense primers derived from exon 9 of the trout irak3 gene (c.f. Figure 2A) produced two major bands of different length representing fragments of the truncated (marked with an asterisk) and the full-length transcript. DNA-marker bands are shown on the left. (B) Schematic comparison of the full-length (irak3- $m$ ) and truncated (irak3-a) transcripts of trout with the predicted Irak3-encoding fragment of salmon. Exons are numbered and sequences are drawn to scale; different colors indicate characteristic Irak3 domains as in Figures 1, 2. The homolog sequence shared by the coding irak3 fragment of the truncated variant and the salmon sequence is indicated with a blue dotted line. The orange dotted line marks the position of the nonamer sequence motif (underlined) not found in the full-length transcript. The alignment of a section containing the nonamer-sequence in the truncated trout sequence (OM; LN828695) and in the salmon sequence (SS; XM_014208880) is shown on the right. Start and end nt positions of the fragments are indicated. The sequence of the RACE primer f2 is shown in blue. The potential accessory splice site is framed in orange; the stop codon of the truncated irak3 transcripts is marked in red. (C) Alignment of the $5^{\prime}$-UTRs of the truncated irak3 transcript from trout (OM; LR213462) and the predicted irak3 sequence from salmon (SS; XM_014208880). Identical bases in the SS sequence are indicated by dots. The retroposon sequence is highlighted in bold.

of numerous inhibitory factors (illrl1, tollip, inpp5d, tnfaip $3, c f h$, $c d 59, a 2 m, i l 4 / 13, t g f b-2, g p r 84)$ mostly at 24 hpi. In contrast, the expression of only a few regulators ( $n f k b i a$, socs 1, and gpr84) increased in PBLs, especially at 12 hpi. In the liver, many genes were down-regulated, including complement-system regulators, some of which were not detectable in other cell/tissue types.

Certain genes were clearly upregulated across all cells/tissues and most time points. Tnfaip3/a20 and the three nfkbia variants all significantly increased in the liver and head kidney at almost all times after infection, and considerable copy numbers were found in the PBLs as well. Socs 1 and gpr84 were also strongly upregulated in all three cell/tissue types, but only at $12 \mathrm{hpi}$. Therefore, these data reveal that the A.-salmonicida infection triggered a broad variety of factors and mechanisms that counteract inflammation, validating that this infection trial was successful.

\section{Overexpression of irak3-a in Mammalian Cells Reduces Cell Viability}

Previous investigations revealed that IRAK3 is equally distributed in the cytoplasm and nucleus of human cells and shifts toward the cytoplasm upon immune stimulation $(45,46)$. We wanted to see, whether this also applies to the ortholog from trout and whether the Irak3 variants might alter this pathogen-stimulated spatial redistribution of the factor. To this end, we transfected the full-length irak3 or selected variants tagged with GFP into HEK-293 cells together with a plasmid expressing bovine TLR2 (Figure 5A). Twenty-four hours after transfection, we observed that the full-length factor Irak3-m and its severely crippled splice variant $\mathrm{m}^{\prime \prime}$ were almost uniformly distributed in the cytoplasm of the cells. The truncated Irak3-a, featuring the N-terminal half of the full-length factor and notably lacking the entire C-terminal domain, was visible both in the cytoplasm and in the nucleus (Figure 5B). This was seen in multiple transfections performed with different plasmid preparations. A stimulation of the cells with $10 \mathrm{ng} / \mathrm{ml} \mathrm{Pam}{ }_{2} \mathrm{CSK}_{4}$ did not change the localization (data not shown).

Strikingly, we found a higher proportion of rounded cells in those cultures that were transfected with the truncated Irak3a variant (c.f. Figure 5A). Since the rounding up of otherwise fibroblast-like HEK-293 cells indicates cell death, we quantified the dead cells in cultures that were transfected with one of the three variants $\mathrm{m}$, $\mathrm{a}$, and $\mathrm{m}^{\prime \prime}$. The fraction of dead cells doubled to $>12 \%$ in cells transfected with irak3-a compared to non-transfected cells or cells transfected with irak3-m and $m^{\prime \prime}$ (Figure 5C). The in vivo most abundantly expressed irak3transcript variant appears to have a somewhat cytotoxic effect, at least if massively overexpressed. 


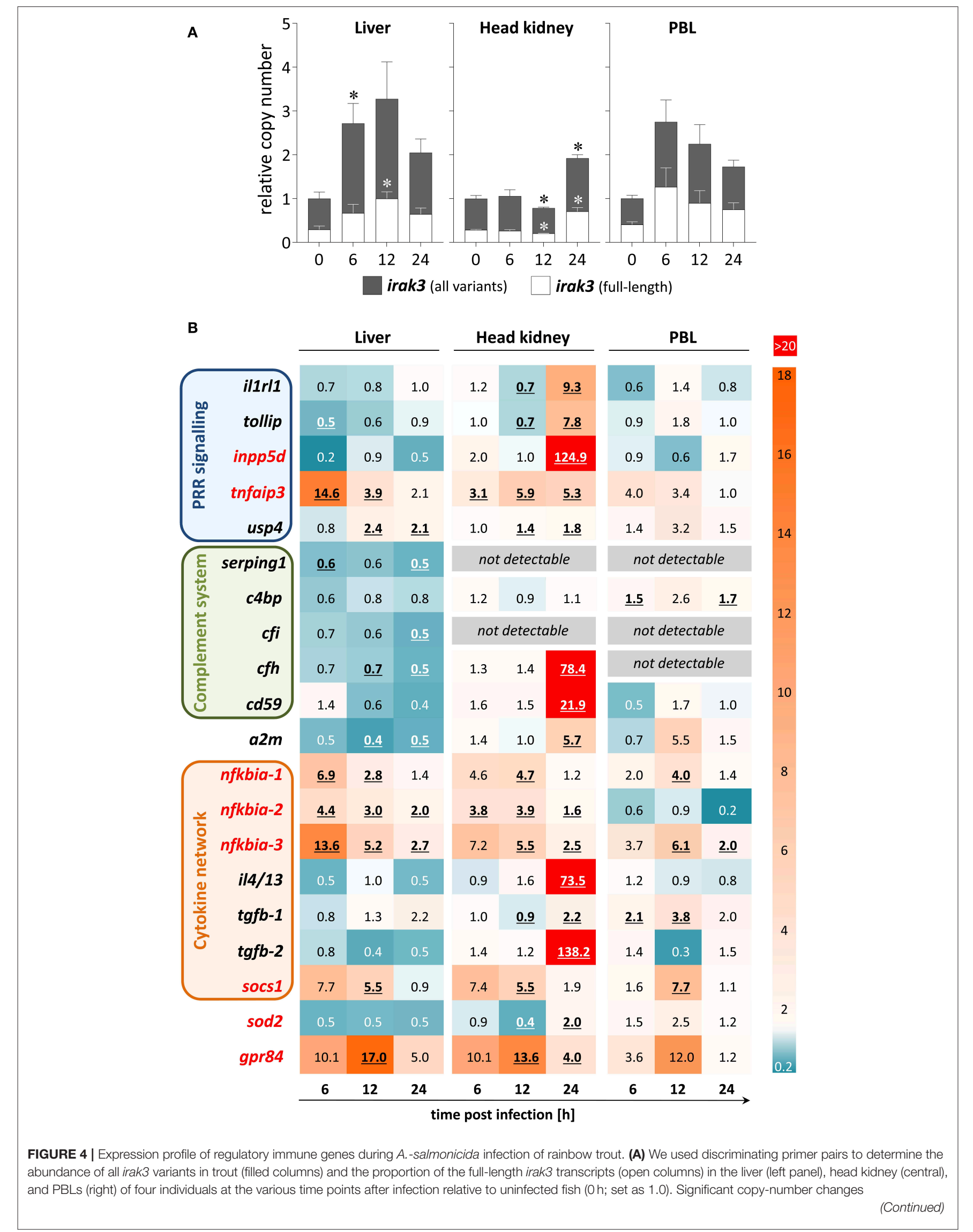


FIGURE 4 | ( $)<0.05)$ are marked with an asterisk (*); error bars indicate SEM. (B) The HeatMap illustrates the averaged fold-change values (according to the legend on the right) of the mRNA concentrations measured in the liver (left panel), head kidney (central), and PBLs (right) at the time points after infection indicated below the scheme relative to controls (set as 1.0). The quantified transcripts are listed as gene symbols on the left and categorized according to their affiliation to immune processes; orthologs whose expression is IRAK3-dependent in mammals according to Zhou et al. (5) are marked in red. Significant copy-number changes ( $p<0.05$ ) are underlined. All expression values were normalized against the geometric means of the reference genes eef1a1 and rps5 as evaluated with the qBase+ software.

A
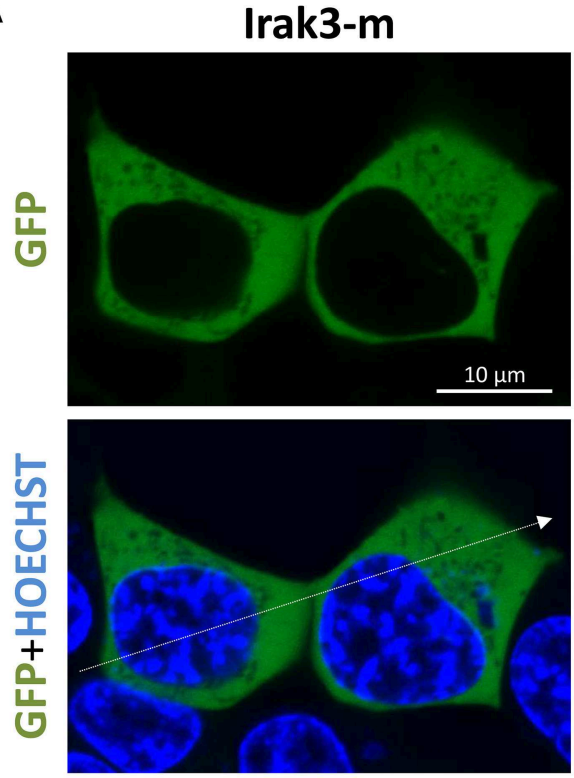

B

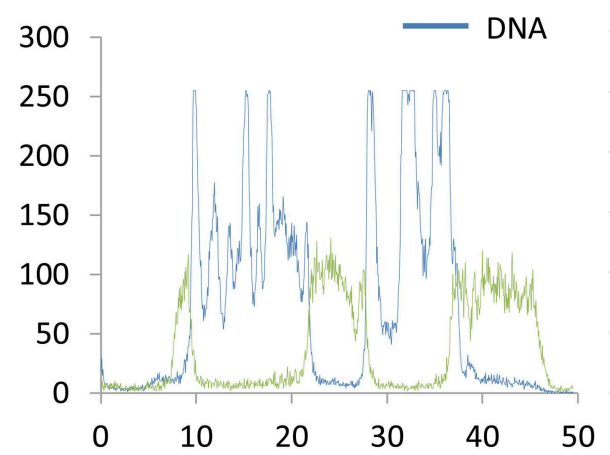

C

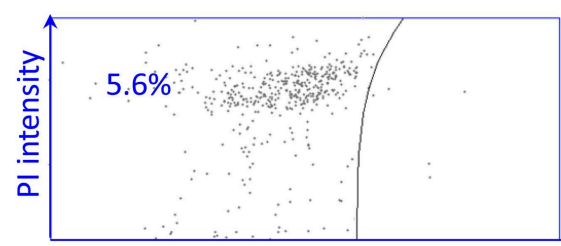

Irak3-a
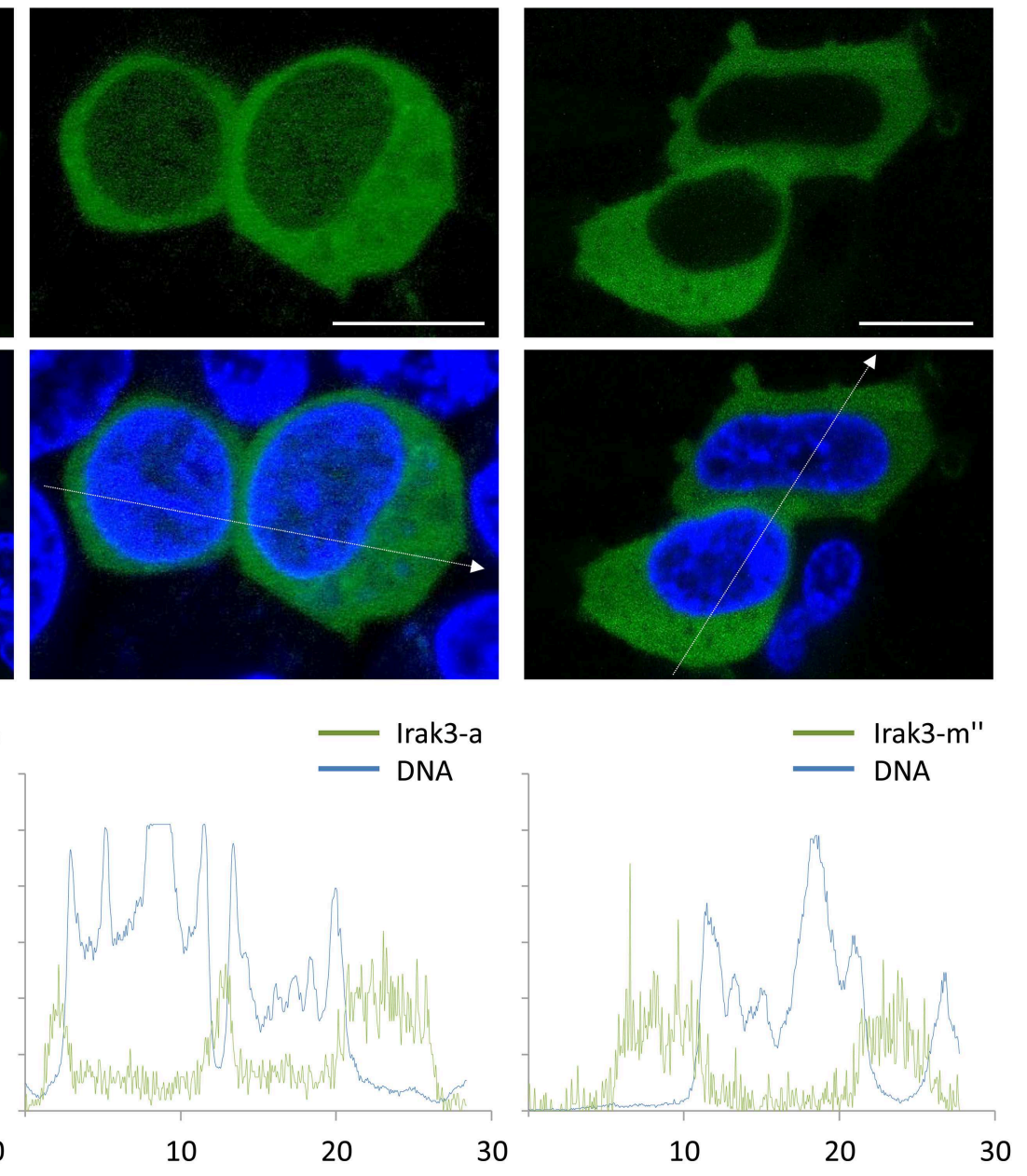

Irak3-a

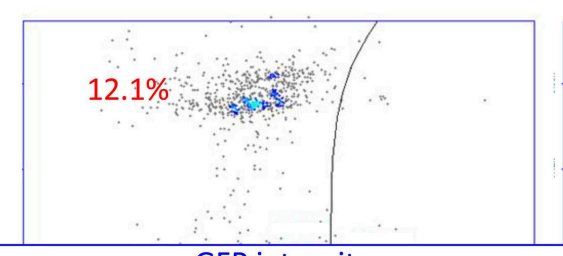

GFP intensity

FIGURE 5 | Overexpression of full-length factor Irak3 $\mathrm{m}$ and variants a, and $\mathrm{m}^{\prime \prime}$ in HEK-293 cells. (A) Human HEK-293 cells were transfected with plasmids expressing the GFP-tagged Irak3 variants, the full-length factor $\mathrm{m}$, truncated factor a, and splice variant $\mathrm{m}^{\prime \prime}$. Cells were visualized $24 \mathrm{~h}$ after transfection with a confocal laser-scanning microscope. Nuclei were stained with Hoechst 33342 (blue). Scale bars represent $10 \mu \mathrm{m}$ in all images. (B) Profile of fluorescence intensities (ordinate) recorded at specific locations (abscissa) across the cell following that path as indicated by the dotted arrows in 4A. (C) Live/dead assay of HEK-293 cells quantified the proportion of dead cells in the total cell count after the overexpression of full-length Irak3-m, truncated Irak3-a or spliced Irak3-m" factors. The left part of each of the three dot plots shows the number of dead (PI-stained) GFP-negative cells and the right part shows the number of living GFP-positive (irak3-expressing) cells. One representative result is shown. 


\section{Full-Length Irak3-m and Truncated Variant a Increase Basal NF- $\mathrm{B}$ Levels, but Do Not Reduce Stimulation-Induced NF- $\kappa$ B Levels in Mammalian Cells}

In the next step, we investigated the influence of the Irak3 variants $\mathrm{m}, \mathrm{a}, \mathrm{m}^{\prime \prime}$, and $\mathrm{l}$ (without GFP tag) on TLR2-induced NF- $\kappa B$ activation in mammalian HEK-293 cells. We transfected increasing amounts of constructs that express these factors into those cells. The co-transfection of an NF- $\mathrm{KB}$-responsive luciferase-reporter gene allowed monitoring the NF- $\mathrm{KB}$ activity. Considering the effect of overexpressed Irak 3 factors on the basal NF- $\kappa \mathrm{B}$ activity without stimulating TLR2 signaling, we found that overexpressing the full-length factor $\mathrm{m}$ and the truncated factor a substantially increased the basal level of NF- $\kappa$ B activity in a dose-dependent fashion (Figure 6A), eventually to $5.4 \pm 0.4$ or $2.5 \pm 0.2$-fold (factors $\mathrm{m}$ and a, respectively) if the highest dose ( 2 $\mu \mathrm{g}$ of the plasmids) was used. In contrast, overexpression of the more severely shortened splice variants 1 and $\mathrm{m}^{\prime \prime}$ induced only minor levels of active NF- $\kappa$ B.

Stimulating TLR2 signaling with the PAMPs $\mathrm{Pam}_{2} \mathrm{CSK}_{4}$ and FSL-1 in non-irak3-transfected HEK-293 cells increased the level of active NF- $\kappa$ B by $20.2 \pm 0.4$-fold compared with unstimulated non-irak3-transfected cells. Overexpressing the full-length factor $\mathrm{m}$ and the truncated variant a lowered the TLR2-signalinginduced degree of NF- $\mathrm{KB}$ activation down to $4.0 \pm 0.2$ or 2.8 \pm 0.3 -fold, respectively, compared to identically transfected, unstimulated controls. Splice variant 1 was basically ineffective (Figure 6B). Taking into account the stimulatory effect of the factors $\mathrm{m}$ and $\mathrm{a}$ on the basal NF- $\mathrm{BB}$ activity in the cells, it becomes clear that none of the transfected Irak3 variants substantially altered the ligand-dependent stimulation of NF$\kappa \mathrm{B}$ (Figure 6C). Altogether, the effect of the Irak3 variants on dampening the stimulated NF- $\kappa B$ activity was rather modest, not dose-dependent, and most likely independent from the properties of the transfected constructs.

We obtained almost congruent results when using heat-killed E. coli bacteria instead of PAMPs to stimulate HEK cells (data not shown). In addition, we also examined the effect of isoforms of the truncated irak 3 variants $(\mathrm{g}, \mathrm{h}, \mathrm{k})$, but we did not observe any differences in modulating the levels of active NF- $\mathrm{\kappa B}$ compared with Irak3 variant a (data not shown).

\section{Splice Variant irak3-m", but Neither the Full-Length nor the Truncated Variants, Reduces the Expression of Pro-Inflammatory Interleukins in Salmonid Cells}

We examined the potentially different physiological significance of the prototypic Irak 3 and its shorter variants. To this end, we overexpressed the full-length irak3, the truncated variant a and the splice variants $\mathrm{m}^{\prime \prime}$ and $\mathrm{l}$ in the salmonid cell line CHSE-214 and quantified their influence on the transcript levels of selected immune genes (Figure 7). Transfected cells and non-transfected controls were stimulated with a mixture of the TLR3 ligand poly (I:C) and the TLR5 ligand flagellin for $6 \mathrm{~h}$. qPCR analyses of irak3-transcript levels revealed that overexpression of the fulllength irak 3 factor increased the basal irak3-transcript level in unstimulated cells by approximately 2,000-fold above the level of $\sim 25$ copies per ng of total RNA measured in non-transfected CHSE-214 cells.

Stimulating the non-transfected control cells for $6 \mathrm{~h}$ significantly increased the expression of the pro-inflammatory cytokines $i l 1 b$ and cxcls by $\sim 11$-fold as well as the expression of the inflammation dampener nfkbia-1-3 (3.9- to 5.5-fold), tnfaip3 (2.6-fold), and grp84 (2.4-fold) (Figure 7). Surprisingly, overexpression of neither the full-length irak 3 factor $\mathrm{m}$, nor the truncated factors a and splice variant 1 caused any noteworthy changes in the expression of the selected indicator genes for monitoring inflammation. In stark contrast, splice variant $\mathrm{m}^{\prime \prime}$ clearly and significantly decreased the transcript levels of illb and $c x c l 8$ by a $>5$-fold, accompanied by a slight increase in inpp5d copies ( $\sim 2$-fold) over the levels found in stimulated but non-transfected cells. The 3-h stimulation yielded similar effects, albeit to a lesser extent (Supplementary Figure 1).

\section{DISCUSSION}

The interleukin-1-receptor-associated kinase 3 (IRAK3) was identified as a negative feedback regulator of inflammatory events $(47,48)$ and hence as a relevant factor for properly calibrating the immune response against infections. Its counterpart in the economically important salmonids had not yet been examined in more detail (1).

\section{At Least Two and Possibly More Genes Encode Irak3 in Rainbow Trout}

At the outset of our study, we derived an irak3-consensus sequence from our sequence data obtained previously in an RNAseq analysis of rainbow-trout-tissue samples. An alignment of the resulting consensus sequence with database entries of genomic DNA sequences suggested the existence of two different, yet closely related irak 3 genes that are encoded in rainbow-trout genome. Thirteen exons encode the full-length Irak 3 factor in this salmonid species.

The detection of severely truncated cDNA sequences featuring a nonameric sequence, which is absent in both the full-length irak3-cDNA sequences and the two different genomic irak3sequences, might suggest that these truncated variants are encoded by a third gene copy. However, we identified a highly similar counterpart to this nonamer in the $3^{\prime}$-UTR of an incomplete irak 3 transcript from Atlantic salmon. It might be plausible that the truncated transcripts from trout result from splicing a section of the $3^{\prime}$ UTR to a degenerated copy of exon 9. This hypothetic copy may reside in an intronic region of the irak3 gene similar to the fragments of exon 5, exon 7, and exon 9 within particular introns of the irak 3 genes. This could explain why the same nonameric sequence motif is found in two different transcripts featuring truncated exon-9 sequences of either 151-nt or 110-nt length. That assumption is supported by the fact that the respective nonameric sequence contains the motif TGCTT, which has previously been identified in an analysis of $>20,000$ 
A

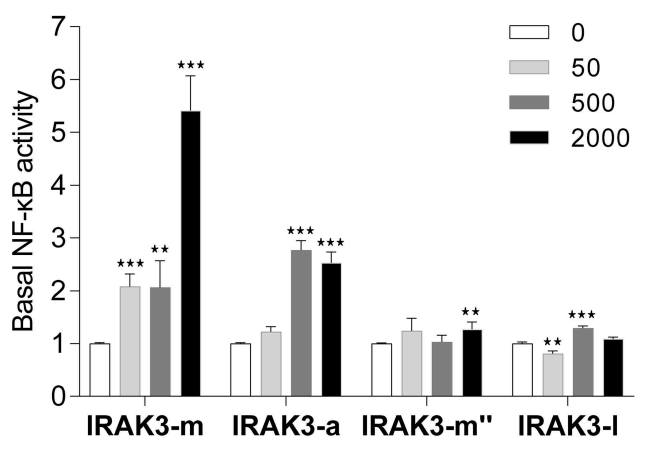

B

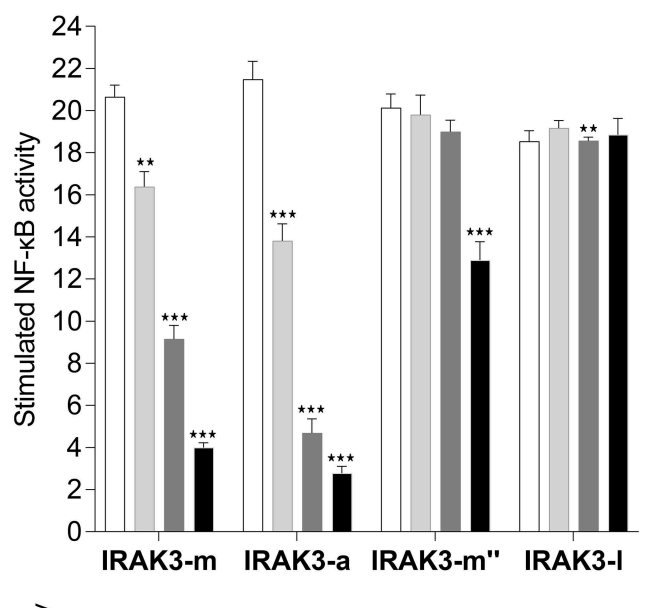

C

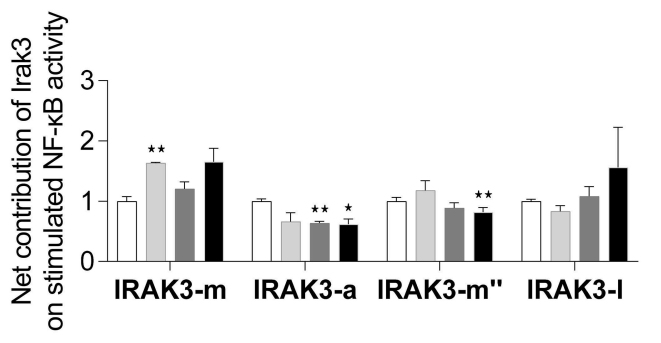

FIGURE 6 | Reporter-gene analysis assessing the influence of Irak-3 factors on NF-kB activity in HEK-293 cells. HEK-293 cells were co-transfected with constructs expressing the bovine TLR2 and the mammalian ELAM-driven NF- $\kappa$ B-luciferase reporter together with increasing amounts of the plasmids (gray-scaled columns) that express the irak3 variants $\mathrm{m}, \mathrm{a}, \mathrm{m}^{\prime \prime}$, and I. (A) Fold-change values (ordinate) of the basal luciferase activity $24 \mathrm{~h}$ after transfection of Irak3-encoding plasmids, relative to the control (open columns) having received the empty plasmid only and no stimulation. The tertiary structures of the transfected irak3 variants are displayed below the diagram. (B,C) Fold-change values of the luciferase activity after stimulation of TLR2 signaling with $10 \mathrm{ng} / \mathrm{ml} \mathrm{Pam}_{2} \mathrm{CSK} 4 \mathrm{and} 100 \mathrm{ng} / \mathrm{ml} \mathrm{FSL}-1 \mathrm{for} 24 \mathrm{~h}$, (B) relative to unstimulated control cells having been transfected with the same amount of the respective irak3-encoding plasmids, (C) relative to stimulated control cells transfected with the empty plasmid. Mean values from 2 or 3 independent experiments, each assayed in triplicate, are given. Statistical significance compared with the control group was assessed using one-way ANOVA $\left({ }^{*} p<0.05 ;{ }^{* *} p<0.01 ;{ }^{* *} p<0.001\right)$.

human mRNAs as one of the 10 most frequent "accessory splicing signals" $(49,50)$.

In mammals, at least half of all full-length transcripts appear together with a splice variant (51). Splice variants also exist from IRAK3 transcripts. For example, splice variant $\operatorname{IRAK3\Delta (2)}$ is known in humans and $\operatorname{IRAK3\Delta }(9-11)$ in mice (13). We also found spliced transcript variants that are clearly derived from the transcripts encoding the full-length or the truncated factor. In some cases, exons are spliced-out using the canonical splice-donor and acceptor dinucleotides flanking the enclosed intron. In other cases, the RNA splicing machinery apparently uses alternative more $5^{\prime}$-located splicedonor dinucleotides. This produces crippled exon sequences, which are incorporated into the resulting transcripts $\left(b^{\prime}, c^{\prime \prime}\right.$, $\left.\mathrm{f}, \mathrm{m}^{\prime}, \mathrm{m}^{\prime \prime}\right)$. Intriguingly, splicing at alternative, non-canonical splice-acceptor or -donor sites apparently produces an even larger proportion of differently shortened transcripts. We recently described a similar observation for the acute-phase gene $t c b p$ coding for the trout C-polysaccharide binding protein (39). The usage of non-canonical splice sites may thus be a quite common phenomenon in teleost fish and salmonids in particular. Apparently, this species complex is still struggling with the consequences of the recent whole-genome duplication
$(41,52)$ to sort out the most efficient gene copies from an excessive number.

\section{High Selection Pressure Rests on the Pseudokinase Domain of Irak3 From Rainbow Trout}

Within the 1,920 nt ORF of the irak3 consensus sequence, we detected 45 single-nucleotide changes. Hence, about every 40 th base was found to be variable, potentially yielding more than $2^{45}=3 \times 10^{13}$ combinations. A recent report indicates that on average every 64th nucleotide position may be polymorphic in the pseudotetraploid genome of rainbow trout (42). Our study thus revealed an even more frequent occurrence of nucleotide exchanges in the irak 3 sequences of rainbow trout. The frequency of SNCs appears to be gene-specific, since the trout irak4 paralog of irak3, for instance, revealed only six SNCs in a 1,425 nt sequence [Supplementary Figure 2; (22)].

Mapping the 29 non-synonymous SNCs on the full-length irak3-consensus sequence from rainbow trout illustrates that the pseudokinase domain is affected by the fewest aa-residue exchanges compared to the other three Irak3 domains. This pseudokinase domain, which is obviously under a higher 


\begin{tabular}{|c|c|c|c|c|c|c|}
\hline & \multicolumn{5}{|c|}{$6 \mathrm{~h}$ stimulated } & \\
\hline & & \multicolumn{4}{|c|}{ + Irak3 } & \\
\hline & & $-m$ & $-\mathbf{a}$ & $-m^{\prime \prime}$ & - I & \\
\hline il1b & $10.7^{*}$ & 12.3 & 11.5 & $\underline{4.0}$ & 10.8 & 14 \\
\hline $\mathrm{cxcl} / 8$ & $11.4^{*}$ & 12.0 & 12.4 & 4.1 & 13.3 & \\
\hline inpp5d & 0.8 & 1.4 & 0.5 & 1.9 & 0.4 & \\
\hline tnfaip3 & $2.6^{*}$ & 1.5 & 3.5 & 1.1 & 3.3 & 1 \\
\hline usp4 & 0.8 & 0.7 & 0.9 & 0.6 & 0.8 & \\
\hline nfkbia-1 & $4.1^{*}$ & $\underline{5.5}$ & 3.6 & 4.3 & 4.4 & 8 \\
\hline nfkbia-2 & $3.9^{*}$ & 4.1 & 3.6 & 3.2 & 4.4 & \\
\hline nfkbia-3 & $5.5^{*}$ & 5.5 & 4.4 & 2.8 & 5.5 & 6 \\
\hline $\operatorname{tgfb-2}$ & 1.4 & 1.4 & 1.1 & 1.2 & 1.3 & \\
\hline socs 1 & & not & detect & able & & \\
\hline $\operatorname{sod} 2$ & 1.1 & 0.9 & 0.9 & 1.0 & 0.9 & 2 \\
\hline gpr84 & $2.4^{*}$ & 2.0 & 3.2 & 1.7 & 2.8 & \\
\hline
\end{tabular}

FIGURE 7 | Expression profiling of stimulated Irak3-overexpressing CHSE-214 cells. The HeatMap illustrates the averaged fold-change values (according to the legend on the right) of the mRNA concentrations measured in CHSE cells $6 \mathrm{~h}$ after stimulation with $10 \mu \mathrm{g} / \mathrm{ml}$ poly $(\mathrm{l}: \mathrm{C})$ and $100 \mathrm{ng} / \mathrm{ml}$ flagellin, relative to unstimulated control cells (set as 1.0). The quantified transcripts are listed as gene symbols on the left; orthologs whose expression is IRAK3-dependent in mammals according to Zhou et al. (5) are highlighted in red. Significant copy-number changes $(p<0.05)$ of stimulated vs. non-stimulated

untransfected cells are marked with asterisks; significant copy-number changes of stimulated non-transfected vs. transfected cells are underlined. All expression values were normalized against the geometric means of the reference genes eef1a1 and rps5.

selection pressure, discriminates the inflammation-supporting IRAK members -1 and -4 from the negatively regulating IRAK 3 $(3,12)$. To our knowledge, there is no evidence yet that the pseudokinase domain of IRAK3 orthologs lacks phosphorylation activity. In general, the pseudokinase domain has so far received only little scientific attention. Therefore, we do not know much about the biological significance of exchanged aa residues within this domain.
The domain-mapping-of-disease-mutations database currently lists 15 non-synonymous SNPs in the $<2 \mathrm{~kb}$ ORF of the human IRAK3 gene. Several studies have proven significant associations between a particular SNP in one of the resulting IRAK3 variants and unbalanced immune reactions, including (i) asthma (53, 54), (ii) sepsis (55) and sepsis-induced acute lung injury (56), as well as (iii) a positive response to treatment in rheumatoid arthritis (57), and (iv) protection against Bordetella pertussis after vaccination (58). Additionally, certain SNPs of the human IRAK3 gene are associated with the risk of cancer (59-61). Clearly, our study was not designed to analyze the physiological effects of SNPs/SNCs. It remains to be seen if any of these many Irak 3 variants detected in our study are associated with a disease trait in rainbow trout.

\section{Irak3 Variants Differentially Activate Basal NF- $\kappa$ B Levels, but Not Their Final Level After Stimulation}

We selected four major structural variants of Irak3 from rainbow trout to study and compare their functions in vitro in the human HEK-293-cell system. This cell line is a well-established "workhorse" for the heterologous expression of immune factors from fish $(23,36,39,62-64)$, especially for the reconstitution of the TLR-signaling cascade. The chosen Irak 3 factors included the prototypic full-length Irak3-m factor (639 aa), the truncated Irak3-a variant lacking a part of the pseudokinase and the complete C-terminal domain (347 aa), and the splice variant Irak3- $\mathrm{m}^{\prime \prime}$ lacking the ProST and the pseudokinase domain (199 aa). We were also curious to see, whether IRAK3-l, which consists only of a death domain (91 aa), would be functional. The HEK-293 cells were transfected with increasing amounts of plasmids that express either one out of the four selected Irak3 variants together with a plasmid expressing the bovine TLR2 and an NF- $\mathrm{KB}$-responsive reporter vector. This experimental setup accounted for the well-explored fact that TLR signaling activates the NF- $\mathrm{KB}$-transcription-factor complex (10) and should allow IRAK3 to counteract NF- $\mathrm{KB}$-induced proinflammatory processes.

The overexpression of the full-length factor $\mathrm{m}$ and the truncated factor a from rainbow trout significantly increased basal NF- $\mathrm{KB}$ activity, while the shorter splice variants $\mathrm{m}^{\prime \prime}$ and 1 were basically ineffective. Modulation of basal NF$\kappa \mathrm{B}$ activity was not necessarily expected, since overexpressing other regulatory factors of the TLR-signaling cascade, such as Il1rl1/St2 (36) or Irak4 from rainbow trout (22), left the level of basal NF-kB activity unchanged. The different modes of action of the full-length Irak 3 factor $\mathrm{m}$ and its variants $\mathrm{a}, \mathrm{m}^{\prime \prime}$, and 1 also became evident after stimulating TLR2transfected HEK-293 cells with relevant PAMPs. Noteworthy, the summation of basal and induced NF-кB-induction folds yielded, in effect, similar values for the final NF-кB-activity levels after stimulation. It was rather unexpected that the overexpression of full-length irak3- $m$ did not alter the final level of NF-кB activity after stimulation with TLR2 ligands, given that Irak3 has often been proven to be a dampener of TLR-dependent inflammation $(12,47,48,65)$. However, a survey of the pertinent 
literature showed that NF- $\kappa \mathrm{B}$ levels after pathogen-dependent stimulation has not often been used as a read-out system. The first analysis on human IRAK3 (alias IRAK-M) 20 years ago demonstrated that overexpressed IRAK3 increased basal NF- $\kappa$ Bactivity levels without stimulation (3). This is generally in line with subsequent studies $(4,28)$ and also with our findings. Many other reports on IRAK3 function did not examine its direct impact upon the TLR-mediated activation of NF- $\kappa \mathrm{B}$ activity, but instead used different read-out systems to validate the inflammation-dampening effects of IRAK3, such as the level of cytokine-gene expression $(13,66,67)$. We show here that Irak3 from rainbow trout does not directly target NF-кB to inhibit inflammatory processes.

Notwithstanding, our overexpression experiment in HEK-293 cells proved that the truncated Irak3 variant a increases the basal level of activated NF- $\kappa B$ almost as efficient as the fulllength variant, although it lacks the entire $\mathrm{C}$-terminal domain. This domain is apparently not involved in the mechanism that regulates the observed effect. Parallel microscopic observations detected a, perhaps unrelated to NF- $\kappa \mathrm{B}$ activation, difference between full-length and the truncated Irak3 variants. We found that the truncated variant Irak3-a increased cell death, in contrast to the full-length variant. Although the death domain is a wellexplored structural requirement for the execution of apoptotic processes (68), there is no evidence, to our knowledge, that IRAK3 directly affects apoptosis in cells. For this reason, we can only speculate whether the physiological expression of the C-terminally truncated Irak3-a variant has a toxic effect on cells in vivo.

\section{The Irak3 Splice Variant m" May Act as a Scavenger Molecule of TLR Signaling}

Our studies conducted in the salmonid CHSE-214 model cells focused on the Irak3-dependent modulation of immune-gene expression after stimulating the TLR axis. We found that the stimulation of immune-gene expression is largely uninfluenced by the overexpression of either the full-length factor irak3-m or its variants a or 1 . We note in this regard that previous studies on the function of the mammalian IRAK3 have been performed primarily on macrophages and lung epithelial cells $(13,71)$. An embryonic cell such as CHSE-214 may not provide all the factors required for the correct functioning of Irak3. Moreover, we found a low endogenous expression level of irak 3 in CSHE-214 cells, but it is remarkable that the additional, eventually 2,000-fold increased concentration of the transcripts encoding the Irak3 factors $\mathrm{m}$, a, and $\mathrm{l}$ did not influence at all the induced immunegene expression. Only overexpression of the splice variant $\mathrm{m}^{\prime \prime}$ significantly lowered the expression of il1b and cxcl8. The stimulated induction of these two proinflammatory cytokines is known to heavily depend on the activation of the TLR-signaling cascade. The assumption that Irak 3 splice variant $\mathrm{m}^{\prime \prime}$ hinders TLR signaling is supported by the fact that its overexpression also led to decreased $n f k b i a-3$ expression. It is known from mammals that activated TLR signaling concomitantly induces the expression of NF- $\kappa \mathrm{B}$-inhibitory factors such as NFKBIA (alias IкB $\alpha$ ). This negative feedback loop conceivably prevents excessive NF-кB activation $(69,70)$. The Irak3 splice variant $\mathrm{m}^{\prime \prime}$ consists almost exclusively of the C-terminal domain. It lacks parts of the death domain and the entire ProST region which is required in the mammalian ortholog for interacting with IRAK4 and activating NF-кB (3-5). This particular architecture of $\mathrm{m}^{\prime \prime}$ might prevent its integration (via TIR-TIR interactions) into the TLR-associated myddosome and could explain why only high concentrations of $\mathrm{m}^{\prime \prime}$ reduce the NF- $\kappa \mathrm{B}$ activity levels (c.f. section Irak3 Variants Differentially Activate Basal NF- $\kappa$ B Levels, But not Their Final Level After Stimulation). Our 3D-model analysis shows that $\mathrm{m}^{\prime \prime}$ exposes the C-terminal domain more prominently than the full-length factor Irak3-m. This domain contains the motif Pro-X-Glu-X-X(aromatic/acidic residue), which is crucial for the interaction with the downstream signaling factor TRAF6 (72) and is well-conserved in the fulllength Irak3 factor and its splice variant $\mathrm{m}^{\prime \prime}$. Hence, Irak3$\mathrm{m}^{\prime \prime}$ might perform its inhibitory function on the expression of $i l 1 b$ and $c x c l 8$ by scavenging TRAF6 in a highly efficient way. This could, in turn, reduce the intensity of TLR-mediated NF- $\kappa$ B activation.

It is poorly understood in the mammalian ortholog, how the shortening of the full-length factor impacts the function of IRAK3, as encoded by the respective splice variants. IRAK2 factors might perhaps serve as a paradigm. There are four isoforms of IRAK2 in mouse and two alternatively spliced factors act as inhibitory factors (73), while the other two support the TLR-signal transfer in a positive manner (74). This example illustrates how the splicing of a particular mRNA transcript may reverse the basic function of the original protein and extend its functional spectrum with either additional or even antagonizing aspects.

\section{Expression Profiling Provides no Indications That any of the irak3 Variants From Trout Induces the Expression of Other Immune Regulators}

In parallel to irak3, we profiled the expression of a broader set of immune inhibitors in infected rainbow trout with focus on those genes whose expressions are considered IRAK3-dependent. Previous publications on mammalian models reported that IRAK3 induces the expression of genes coding for SOCS, INPP5D (SHIP1), TNFAIP3 (A20), NFKBIA (IкB $\alpha$ ), SOD2, and GPR84 $(5,15,17)$. In fact, we observed an early upregulation of irak3 transcripts concomitant with increased levels of inpp5d, tnfaip3, nfkbia-2 and -3, sod2, and gpr84 in the head kidney and/or liver. However, our overexpression studies on the salmonid cell line CHSE-214 did not provide any evidence for the involvement of Irak3 factors in stimulating the expression of specific immune inhibitors. Only the overexpression of variant $\mathrm{m}^{\prime \prime}$ led to an increase in the expression of inpp5d.

Using discriminating primers, we determined the abundances of all irak 3 transcripts and the full-length irak 3 transcripts during the infection of trout with A. salmonicida. Within $24 \mathrm{hpi}$, irak 3 transcript levels increased significantly both in the liver and head kidney, but not in PBLs. These results 
complement our previous observation that irak3-transcript levels were elevated at $72 \mathrm{hpi}$ with $A$. salmonicida in the gills of rainbow trout (75). The infection-related increase in the expression of irak3 has previously been reported in embryonic zebrafish (27).

In summary, our in-vivo analyses of selected Irak3 factors from rainbow trout revealed that both, the full-length and the truncated Irak3 factor contain the structural requirements that allow modulating the activation status of NF- $\mathrm{B}$. The splice variant Irak3-m" from trout limits the expression of inflammatory cytokines. However, we found no evidence that Irak3 from trout actually induces the expression of other immune regulators in contrast to its mammalian counterpart.

\section{CONCLUSIONS}

The mammalian IRAK3 factor controls not only the various TLRdependent signaling cascades but also the signal transduction downstream of the interleukin-1 receptor (IL1R1). While only one full-length and one splice variant of human IRAK3 have been reported, we found more than 20 irak 3 cDNA variants in the salmonid fish rainbow trout, which probably stem from two duplicated genes. It is possible that the presence of these several irak3-transcript variants is only a collateral and functionally insignificant consequence of the polyploidization history of salmonids $(41,52)$. Nevertheless, these multiple Irak3 variants may represent not only sheer abundance, but could cover different and/or complementing tasks. The individual irak3 variants from trout could, for instance, integrate specifically into the different cascades mediated by IL1R1 and more than a dozen TLRs $(44,76-79)$ present in pseudo-tetraploid salmonids. Although our study suggests that the trout Irak3 factors do not interfere with the stimulation-dependent NF- $\kappa \mathrm{B}$ activation, we found that only, and perhaps significantly, a specific Irak3splice variant eventually downregulates the expression of certain cytokine genes. This demonstrates that the great structural diversity of the irak3 factors from trout may also translate into some functional diversity.

\section{DATA AVAILABILITY STATEMENT}

The novel datasets generated for this study are included in the manuscript/Supplementary Files. All irak3-cDNA sequences have been submitted to the "European Nucleotide Archive" (project ID: PRJEB29555).

\section{REFERENCES}

1. Rebl A, Goldammer T. Under control: the innate immunity of fish from the inhibitors' perspective. Fish Shellfish Immunol. (2018) 77:328-49. doi: 10.1016/j.fsi.2018.04.016

2. Gosu V, Basith S, Durai P, Choi S. Molecular evolution and structural features of IRAK family members. PLoS ONE. (2012) 7:e49771. doi: 10.1371/journal.pone.0049771

3. Wesche H, Gao X, Li XX, Kirschning CJ, Stark GR, Cao ZD. IRAK-M is a novel member of the pelle/interleukin-1 receptor-associated kinase (IRAK) family. J Biol Chem. (1999) 274:19403-10

\section{ETHICS STATEMENT}

The animal experiment has been approved by the Landesamt für Landwirtschaft, Lebensmittelsicherheit und Fischerei, Mecklenburg-Vorpommern, Germany; LALLF M-V/TSD/7221.3-2.5-008/10.

\section{AUTHOR CONTRIBUTIONS}

H-MS and AR designed the research. TG and H-MS supervised the project. $\mathrm{MV}$ and TG performed RNA-seq experiments. $\mathrm{SH}, \mathrm{JK}$, and $\mathrm{AR}$ cloned Irak3 variants and transfected cells. AR, H-MS, MV, SH, JK, and TG analyzed sequences. HR carried out confocal microscopy and vitality tests. $\mathrm{AR}$ and $\mathrm{SH}$ performed reporter-gene analysis. AR carried out qPCR experiments. AR and H-MS wrote the paper. All authors commented on the manuscript.

\section{FUNDING}

This work was funded by the DFG-Grant SE 326/16-1 from the Deutsche Forschungsgemeinschaft. The European Fisheries Fund (EFF) and the Ministry of Agriculture, the Environment and Consumer Protection Mecklenburg-Western Pomerania (pilot project: Rainbow trout BORN) also supported this project. The publication of this article was funded by the Open Access Fund of the Leibniz Institute for Farm Animal Biology (FBN).

\section{ACKNOWLEDGMENTS}

The technical assistance of A. Deike, B. Schöpel, I. Hennings, L. Falkenthal, and M. Fuchs is greatly appreciated. We thank T. Korytár and B. Köllner (Friedrich-Loeffler-Institut, Institut für Immunologie, Greifswald, Insel Riems, Germany) for performing the infection trial and J. A. Nguinkal (FBN) is acknowledged for his help with blasting the salmonid transcriptomes. Lastly, many thanks to the reviewers of this manuscript for their constructive comments and very useful suggestions.

\section{SUPPLEMENTARY MATERIAL}

The Supplementary Material for this article can be found online at: https://www.frontiersin.org/articles/10.3389/fimmu. 2019.02246/full\#supplementary-material

4. Du J, Nicolaes GA, Kruijswijk D, Versloot M, van der Poll T, van 't Veer C. The structure function of the death domain of human IRAK-M. Cell Commun Signal. (2014) 12:77. doi: 10.1186/s12964-0140077-3

5. Zhou H, Yu M, Fukuda K, Im J, Yao P, Cui W, et al. IRAK-M mediates Tolllike receptor/IL-1R-induced NFKB activation and cytokine production. EMBO J. (2013) 32:583-96. doi: 10.1038/emboj.2013.2

6. Cormican P, Lloyd AT, Downing T, Connell SJ, Bradley D, O'Farrelly C. The avian Toll-Like receptor pathway-subtle differences amidst general conformity. Dev Comp Immunol. (2009) 33:967-73. doi: 10.1016/j.dci.2009.04.001 
7. Lin SC, Lo YC, Wu H. Helical assembly in the MyD88-IRAK4IRAK2 complex in TLR/IL-1R signalling. Nature. (2010) 465:885-90. doi: 10.1038/nature09121

8. Nie L, Cai S-Y, Shao J-Z, Chen J. Toll-like receptors, associated biological roles, and signaling networks in non-mammals. Front Immunol. (2018) 9:1523. doi: 10.3389/fimmu.2018.01523

9. Vijay K. Toll-like receptors in immunity and inflammatory diseases: past, present, and future. Int Immunopharmacol. (2018) 59:391-412. doi: $10.1016 /$ j.intimp.2018.03.002

10. O'Neill LAJ, Golenbock D, Bowie AG. The history of Toll-like receptors - redefining innate immunity. Nat Rev Immunol. (2013) 13:453-60. doi: $10.1038 /$ nri3446

11. Karin M, Lin A. NF-kappaB at the crossroads of life and death. Nat Immunol. (2002) 3:221-7. doi: 10.1038/ni0302-221

12. Janssens S, Beyaert R. Functional diversity and regulation of different interleukin-1 receptor-associated kinase (IRAK) family members. Mol Cell. (2003) 11:293-302. doi: 10.1016/S1097-2765(03)00053-4

13. Kobayashi K, Hernandez LD, Galan JE, Janeway Jr CA, Medzhitov R, Flavell RA. IRAK-M is a negative regulator of Toll-like receptor signaling. Cell. (2002) 110:191-202. doi: 10.1016/s0092-8674(02)00827-9

14. Hassan F, Islam S, Tumurkhuu G, Dagvadorj J, Naiki Y, Komatsu T, et al. Involvement of interleukin-1 receptor-associated kinase (IRAK)-M in toll-like receptor (TLR) 7-mediated tolerance in RAW 264.7 macrophage-like cells. Cell Immunol. (2009) 256:99-103. doi: 10.1016/j.cellimm.2009.01.013

15. van 't Veer C, van den Pangaart PS, van Zoelen MAD, de Kruif M, Birjmohun RS, Stroes ES, et al. Induction of IRAK-M is associated with lipopolysaccharide tolerance in a human endotoxemia model. I Immunol. (2007) 179:7110-20. doi: 10.4049/jimmunol.179.10.7110

16. Liu Z-J, Yan L-N, Li X-H, Xu F-L, Chen X-F, You H-B, et al. Upregulation of IRAK-M is essential for endotoxin tolerance induced by a low dose of lipopolysaccharide in Kupffer cells. J Surg Res. (2008) 150:34-39. doi: 10.1016/j.jss.2007.12.759

17. Xiong $\mathrm{Y}, \mathrm{Medvedev} \mathrm{AE}$. Induction of endotoxin tolerance in vivo inhibits activation of IRAK4 and increases negative regulators IRAK-M, SHIP-1, and A20. J Leukoc Biol. (2011) 90:1141-8. doi: 10.1189/jlb.0611273

18. Zhou Y, Xia Q, Wang X, Fu S. Endotoxin tolerant dendritic cells suppress inflammatory responses in splenocytes via interleukin-1 receptor associated kinase (IRAK)-M and programmed death-ligand 1 (PDL-1). Med Sci Monit. (2018) 24:4798-806. doi: 10.12659/MSM.908242

19. Lyn-Kew K, Rich E, Zeng X, Wen H, Kunkel SL, Newstead MW, et al. IRAK$\mathrm{M}$ regulates chromatin remodeling in lung macrophages during experimental sepsis. PLoS ONE. (2010) 5:e11145. doi: 10.1371/journal.pone.0011145

20. Günthner R, Kumar VRS, Lorenz G, Anders H-J, Lech M. Pattern-recognition receptor signaling regulator mRNA expression in humans and mice, and in transient inflammation or progressive fibrosis. Int J Mol Sci. (2013) 14:1812447. doi: 10.3390/ijms140918124

21. Rebl A, Goldammer T, Fischer U, Köllner B, Seyfert H-M. Characterization of two key molecules of teleost innate immunity from rainbow trout (Oncorhynchus mykiss): MyD88 and SAA. Vet Immunol Immunopathol. (2009) 131:122-6. doi: 10.1016/j.vetimm.2009.03.006

22. Brietzke A, Goldammer T, Rebl H, Korytár T, Köllner B, Yang W, et al. Characterization of the interleukin 1 receptor-associated kinase 4 (IRAK4)-encoding gene in salmonid fish: the functional copy is rearranged in Oncorhynchus mykiss and that factor can impair TLR signaling in mammalian cells. Fish Shellfish Immunol. (2014) 36:206-14. doi: 10.1016/j.fsi.2013.11.005

23. Rebl A, Rebl H, Liu S, Goldammer T, Seyfert H-M. Salmonid Tollip and MyD88 factors can functionally replace their mammalian orthologues in TLR-mediated trout SAA promoter activation. Dev Comp Immunol. (2011) 35:81-7. doi: 10.1016/j.dci.2010.08.012

24. Huang R, Lv J, Luo D, Liao L, Zhu Z, Wang Y. Identification, characterization and the interaction of Tollip and IRAK-1 in grass carp (Ctenopharyngodon idellus). Fish Shellfish Immunol. (2012) 33:459-67. doi: 10.1016/j.fsi.2012.05.025

25. Zhang C-Z, Yin Z-X, He W, Chen W-J, Luo Y-W, Lu Q-X, Weng S-P, Yu X$\mathrm{Q}, \mathrm{He}$ J. Cloning of IRAK1 and its upregulation in symptomatic mandarin fish infected with ISKNV. Biochem Biophys Res Commun. (2009) 383:298-302. doi: 10.1016/j.bbrc.2009.03.137
26. Stein C, Caccamo M, Laird G, Leptin M. Conservation and divergence of gene families encoding components of innate immune response systems in zebrafish. Genome Biol. (2007) 8:R251. doi: 10.1186/gb-2007-8-11-r251

27. Stockhammer OW, Zakrzewska A, Hegedûs Z, Spaink HP, Meijer AH. Transcriptome profiling and functional analyses of the zebrafish embryonic innate immune response to Salmonella infection. J Immunol. (2009) 182:5641-53. doi: 10.4049/jimmunol.0900082

28. Li Y-W, Han R, Wang J-L, Yang M, Dan X-M, Li A-X. Molecular identification and functional characterization of IRAK-3 from a teleost fish, the orangespotted grouper (Epinephelus coioides). Fish Shellfish Immunol. (2018) 81:3839. doi: 10.1016/j.fsi.2018.07.029

29. Goldammer T, Rebl A, Brunner RM, Köbis J, Verleih M, Borchel A, et al. Global Transcriptome Analyses in Two Different Selected Rainbow Trout Strains for Development of Molecular Biomarkers Determining Fish Welfare. Aquaculture Europe 2015 Rotterdam. Available online at: https://www.was. org/easonline/AbstractDetail.aspx?i=4152 (accessed October 21, 2015).

30. Golosova O, Henderson R, Vaskin Y, Gabrielian A, Grekhov G, Nagarajan $\mathrm{V}$, et al. Unipro UGENE NGS pipelines and components for variant calling, RNA-seq and ChIP-seq data analyses. PeerJ. (2014) 2:e644. doi: $10.7717 /$ peerj. 644

31. Mello B. Estimating TimeTrees with MEGA and the TimeTree resource. Mol Biol Evol. (2018) 35:2334-42. doi: 10.1093/molbev/msy133

32. Kelley LA, Sternberg MJE. Protein structure prediction on the Web: a case study using the Phyre server. Nat Protoc. (2009) 4:363-71. doi: 10.1038/nprot.2009.2

33. Sayle RA, Milner-White EJ. RASMOL: biomolecular graphics for all. Trends Biochem Sci. (1995) 20:374.

34. Yang W, Zerbe H, Petzl W, Brunner RM, Gunther J, Draing C, et al. Bovine TLR2 and TLR4 properly transduce signals from Staphylococcus aureus and E. coli, but $\mathrm{S}$. aureus fails to both activate NF-kappaB in mammary epithelial cells and to quickly induce TNFalpha and interleukin-8 (CXCL8) expression in the udder. MolImmunol. (2008) 45:1385-97. doi: 10.1016/j.molimm.2007.09.004

35. Shaw G, Morse S, Ararat M, Graham FL. Preferential transformation of human neuronal cells by human adenoviruses and the origin of HEK 293 cells. FASEB J. (2002) 16:869-71. doi: 10.1096/fj.01-0995fje

36. Rebl A, Rebl H, Köbis JM, Goldammer T, Seyfert H-M. ST2 from rainbow trout quenches TLR signalling, localises at the nuclear membrane and allows the nuclear translocation of MYD88. Dev Comp Immunol. (2017) 67:139-52. doi: 10.1016/j.dci.2016.10.009

37. Flecknell P. Replacement, reduction and refinement. ALTEX. (2002) 19:73-8. Available online at: https://www.altex.org/index.php/altex/article/view/1106

38. Bowers RM, Lapatra SE, Dhar AK. Detection and quantitation of infectious pancreatic necrosis virus by real-time reverse transcriptase-polymerase chain reaction using lethal and non-lethal tissue sampling. J Virol Methods. (2008) 147:226-34. doi: 10.1016/j.jviromet.2007.09.003

39. Köbis JM, Rebl H, Goldammer T, Rebl A. Multiple gene and transcript variants encoding trout C-polysaccharide binding proteins are differentially but strongly induced after infection with Aeromonas salmonicida. Fish Shellfish Immunol. (2017) 60: 509-19. doi: 10.1016/j.fsi.2016.11.021

40. Palti Y, Genet C, Gao G, Hu Y, You FM, Boussaha M, et al. A second generation integrated map of the rainbow trout (Oncorhynchus mykiss) genome: analysis of conserved synteny with model fish genomes. Mar Biotechnol. (2012) 14:343-57. doi: 10.1007/s10126-011-9418-z

41. Berthelot C, Brunet F, Chalopin D, Juanchich A, Bernard M, Noël B, et al. The rainbow trout genome provides novel insights into evolution after whole-genome duplication in vertebrates. Nat Commun. (2014) 5:3657. doi: $10.1038 /$ ncomms 4657

42. Gao G, Nome T, Pearse DE, Moen T, Naish KA, Thorgaard GH, et al. A new single nucleotide polymorphism database for rainbow trout generated through whole genome resequencing. Front Genet. (2018) 9:147. doi: $10.3389 /$ fgene.2018.00147

43. Kollewe C, Mackensen A-C, Neumann D, Knop J, Cao P, Li S, et al. Sequential autophosphorylation steps in the interleukin-1 receptor-associated kinase-1 regulate its availability as an adapter in interleukin-1 signaling. J Biol Chem. (2004) 279:5227-36. doi: 10.1074/jbc.M309251200

44. Brietzke A, Korytáŕ T, Jaros J, Köllner B, Goldammer T, Seyfert H$\mathrm{M}$, et al. Aeromonas salmonicida infection only moderately regulates expression of factors contributing to Toll-like receptor signaling but 
massively activates the cellular and humoral branches of innate immunity in rainbow trout (Oncorhynchus mykiss). J Immunol Res. (2015) 2015:901015. doi: 10.1155/2015/901015

45. Udgata A, Qureshi R, Mukhopadhyay S. Transduction of functionally contrasting signals by two mycobacterial ppe proteins downstream of TLR2 receptors. J Immunol. (2016) 197:1776-87. doi: 10.4049/jimmunol.1501816

46. Su J, Xie Q, Wilson I, Li L. Differential regulation and role of interleukin-1 receptor associated kinase-M in innate immunity signaling. Cell Signal. (2007) 19:1596-601. doi: 10.1016/j.cellsig.2007.02.009

47. Flannery S, Bowie AG. The interleukin-1 receptor-associated kinases: critical regulators of innate immune signalling. Biochem Pharmacol. (2010) 80:198191. doi: $10.1016 /$ j.bcp.2010.06.020

48. Rothschild DE, McDaniel DK, Ringel-Scaia VM, Allen IC. Modulating inflammation through the negative regulation of NF-KB signaling. J Leukoc Biol. (2018) 103:1131-50. doi: 10.1002/JLB.3MIR0817-346RRR

49. Suyama M, Harrington ED, Vinokourova S, von Knebel Doeberitz M, Ohara O, Bork P. A network of conserved co-occurring motifs for the regulation of alternative splicing. Nucleic Acids Res. (2010) 38:7916-26. doi: $10.1093 /$ nar/gkq705

50. Voelker RB, Berglund JA. A comprehensive computational characterization of conserved mammalian intronic sequences reveals conserved motifs associated with constitutive and alternative splicing. Genome Res. (2007) 17:1023-33. doi: $10.1101 /$ gr.6017807

51. Modrek B, Lee C. A genomic view of alternative splicing. Nat Genet. (2002) 30:13-9. doi: 10.1038/ng0102-13

52. Macqueen DJ, Johnston IA. A well-constrained estimate for the timing of the salmonid whole genome duplication reveals major decoupling from species diversification. Proc R Soc B Biol Sci. (2014) 281:20132881. doi: 10.1098/rspb.2013.2881

53. Balaci L, Spada MC, Olla N, Sole G, Loddo L, Anedda F, et al. IRAK-M is involved in the pathogenesis of early-onset persistent asthma. Am J Hum Genet. (2007) 80:1103-14. doi: 10.1086/518259

54. Pino-Yanes M, Sánchez-Machín I, Cumplido J, Figueroa J, Torres-Galván MJ, González R, et al. IL-1 receptor-associated kinase 3 gene (IRAK3) variants associate with asthma in a replication study in the Spanish population. $J$ Allergy Clin Immunol. (2012) 129:573-5.e10. doi: 10.1016/j.jaci.2011.10.001

55. Dong G, Gong J, Li J, Luo Y, Li Z, Li P, et al. Association between gene polymorphisms of IRAK-M and the susceptibility of sepsis. Inflammation. (2013) 36:1087-93. doi: 10.1007/s10753-013-9641-z

56. Pino-Yanes M, Ma S-F, Sun X, Tejera P, Corrales A, Blanco J, et al. Interleukin-1 receptor-associated kinase 3 gene associates with susceptibility to acute lung injury. Am J Respir Cell Mol Biol. (2011) 45:740-5. doi: $10.1165 / \mathrm{rcmb} .2010-0292 \mathrm{OC}$

57. Sode J, Vogel U, Bank S, Andersen PS, Hetland ML, Locht H, et al. Confirmation of an IRAK3 polymorphism as a genetic marker predicting response to anti-TNF treatment in rheumatoid arthritis. Pharmacogenomics J. (2018) 18:81-6. doi: 10.1038/tpj.2016.66

58. Kimman TG, Banus S, Reijmerink N, Reimerink J, Stelma FF, Koppelman $\mathrm{GH}$, et al. Association of interacting genes in the Toll-like receptor signaling pathway and the antibody response to pertussis vaccination. PLOS ONE. (2008) 3:e3665. doi: 10.1371/journal.pone.0003665

59. Rajaraman P, Brenner A V., Butler MA, Wang SS, Pfeiffer RM, Ruder $\mathrm{AM}$, et al. Common variation in genes related to innate immunity and risk of adult glioma. Cancer Epidemiol Biomarkers Prev. (2009) 18:1651-8. doi: 10.1158/1055-9965.EPI-08-1041

60. Bhatnagar R, Dabholkar J, Saranath D. Genome-wide disease association study in chewing tobacco associated oral cancers. Oral Oncol. (2012) 48:831-5. doi: 10.1016/j.oraloncology.2012.03.007

61. Greenman C, Stephens P, Smith R, Dalgliesh GL, Hunter C, Bignell G, et al. Patterns of somatic mutation in human cancer genomes. Nature. (2007) 446:153-8. doi: $10.1038 /$ nature 05610

62. Pietretti D, Vera-Jimenez NII, Hoole D, Wiegertjes GFF. Oxidative burst and nitric oxide responses in carp macrophages induced by zymosan, MacroGard ${ }^{\circledR}$ and selective dectin-1 agonists suggest recognition by multiple pattern recognition receptors. Fish Shellfish Immunol. (2013) 35:847-57. doi: $10.1016 /$ j.fsi.2013.06.022
63. Skjaeveland I, Iliev DB, Strandskog G, Jørgensen JB. Identification and characterization of TLR8 and MyD88 homologs in Atlantic salmon (Salmo salar). Dev Comp Immunol. (2009) 33:1011-7. doi: 10.1016/j.dci.2009.04.007

64. Brietzke A, Arnemo M, Gjøen T, Rebl H, Korytár T, Goldammer T, et al. Structurally diverse genes encode Tlr2 in rainbow trout: The conserved receptor cannot be stimulated by classical ligands to activate NF-кB in vitro. Dev Comp Immunol. (2016) 54:75-88. doi: 10.1016/j.dci.2015.08.012

65. Liew FY, Xu D, Brint EK, O’Neill LAJ. Negative regulation of toll-like receptor-mediated immune responses. NatRevImmunol. (2005) 5:446-58. doi: $10.1038 /$ nri1630

66. Steiger S, Kumar SV, Honarpisheh M, Lorenz G, Günthner R, Romoli S, et al. Immunomodulatory molecule IRAK-M balances macrophage polarization and determines macrophage responses during renal fibrosis. J Immunol. (2017) 199:1440-52. doi: 10.4049/jimmunol.1601982

67. Zhang M, Chen W, Zhou W, Bai Y, Gao J. Critical role of IRAK-M in regulating antigen-induced airway inflammation. Am J Respir Cell Mol Biol. (2017) 57:547-59. doi: $10.1165 / \mathrm{rcmb} .2016-03700 \mathrm{C}$

68. Weber $\mathrm{CH}$, Vincenz $\mathrm{C}$. The death domain superfamily: a tale of two interfaces? Trends Biochem. (2001) 26:475-81. doi: 10.1016/S0968-0004(01)01905-3

69. Ghosh S, Hayden MS. New regulators of NF-kappaB in inflammation. Nat Rev Immunol. (2008) 8:837-48. doi: 10.1038/nri2423

70. Hinz M, Scheidereit C. The IкB kinase complex in NF-кB regulation and beyond. EMBO Rep. (2014) 15:46-61. doi: 10.1002/embr.201337983

71. Hoogerwerf JJ, van der Windt GJW, Blok DC, Hoogendijk AJ, De Vos AF, van 't Veer C, et al. Interleukin-1 receptor-associated kinase M-deficient mice demonstrate an improved host defense during Gram-negative pneumonia. Mol Med. (2012) 18:1067-75. doi: 10.2119/molmed.2011.00450

72. Ye H, Arron JR, Lamothe B, Cirilli M, Kobayashi T, Shevde NK, et al. Distinct molecular mechanism for initiating TRAF6 signalling. Nature. (2002) 418:443-7. doi: 10.1038/nature00888

73. Hardy MP, O'Neill LA. The murine IRAK2 gene encodes four alternatively spliced isoforms, two of which are inhibitory. J Biol Chem. (2004) 279:27699708. doi: 10.1074/jbc.M403068200

74. Muzio M, Ni J, Feng P, Dixit VM. IRAK (Pelle) family member IRAK-2 and MyD88 as proximal mediators of IL-1 signaling. Science. (1997) 278:1612-5.

75. Rebl A, Korytáŕ T, Köbis JM, Verleih M, Krasnov A, Jaros J, et al. Transcriptome profiling reveals insight into distinct immune responses to Aeromonas salmonicida in gill of two rainbow trout strains. Mar Biotechnol. (2014) 16:333-48. doi: 10.1007/s10126-013-9552-x

76. Altmann S, Korytář T, Kaczmarzyk D, Nipkow M, Kühn C, Goldammer $\mathrm{T}$, et al. Toll-like receptors in maraena whitefish: evolutionary relationship among salmonid fishes and patterns of response to Aeromonas salmonicida. (2016) 54:391-401. doi: 10.1016/j.fsi.2016.04.125

77. Arnemo M, Kavaliauskis A, Gjøen T. Effects of TLR agonists and viral infection on cytokine and TLR expression in Atlantic salmon (Salmo salar). Dev Comp Immunol. (2014) 46:139-45. doi: 10.1016/j.dci.2014.03.023

78. Lee PT, Zou J, Holland JW, Martin SAM, Collet B, Kanellos T, et al. Identification and characterisation of TLR18-21 genes in Atlantic salmon (Salmo salar). Fish Shellfish Immunol. (2014) 41:549-59. doi: $10.1016 /$ j.fsi.2014.10.006

79. Lee PT, Zou J, Holland JW, Martin SAM, Kanellos T, Secombes CJ. Identification and characterization of TLR7, TLR8a2, TLR8b1 and TLR8b2 genes in Atlantic salmon (Salmo salar). Dev Comp Immunol. (2013) 41:295305. doi: 10.1016/j.dci.2013.05.013

Conflict of Interest: The authors declare that the research was conducted in the absence of any commercial or financial relationships that could be construed as a potential conflict of interest.

Copyright (c) 2019 Rebl, Rebl, Verleih, Haupt, Köbis, Goldammer and Seyfert. This is an open-access article distributed under the terms of the Creative Commons Attribution License (CC BY). The use, distribution or reproduction in other forums is permitted, provided the original author(s) and the copyright owner(s) are credited and that the original publication in this journal is cited, in accordance with accepted academic practice. No use, distribution or reproduction is permitted which does not comply with these terms. 